Article

\title{
Harmonic Analysis of Grid-Connected Solar PV Systems with Nonlinear Household Loads in Low-Voltage Distribution Networks
}

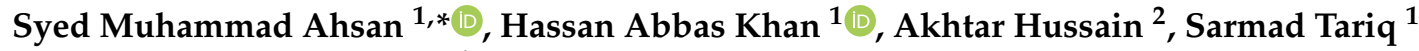 \\ and Nauman Ahmad Zaffar 1 \\ 1 Department of Electrical Engineering, SBA School of Science and Engineering, LUMS, Lahore 54792, Pakistan; \\ hassan.khan@lums.edu.pk (H.A.K.); $15100039 @ 1 u m s . e d u . p k$ (S.T.); nauman.zaffar@lums.edu.pk (N.A.Z.) \\ 2 Department of Electrical Engineering, Incheon National University, Incheon 22012, Korea; \\ hussainakhtar@inu.ac.kr \\ * Correspondence: syed.razvi@lums.edu.pk
}

Citation: Ahsan, S.M.; Khan, H.A.; Hussain, A.; Tariq, S.; Zaffar, N.A. Harmonic Analysis of GridConnected Solar PV Systems with Nonlinear Household Loads in Low-Voltage Distribution Networks. Sustainability 2021, 13, 3709. https:// doi.org/10.3390/su13073709

Academic Editor: Marek Jasinski

Received: 22 February 2021

Accepted: 21 March 2021

Published: 26 March 2021

Publisher's Note: MDPI stays neutral with regard to jurisdictional claims in published maps and institutional affiliations.

Copyright: (c) 2021 by the authors. Licensee MDPI, Basel, Switzerland. This article is an open access article distributed under the terms and conditions of the Creative Commons Attribution (CC BY) license (https:// creativecommons.org/licenses/by/ $4.0 /)$.

\begin{abstract}
Grid-connected rooftop and ground-mounted solar photovoltaics (PV) systems have gained attraction globally in recent years due to (a) reduced PV module prices, (b) maturing inverter technology, and (c) incentives through feed-in tariff (FiT) or net metering. The large penetration of grid-connected PVs coupled with nonlinear loads and bidirectional power flows impacts grid voltage levels and total harmonic distortion (THD) at the low-voltage (LV) distribution feeder. In this study, LV power quality issues with significant nonlinear loads were evaluated at the point of common coupling (PCC). Various cases of PV penetration (0 to $100 \%$ ) were evaluated for practical feeder data in a weak grid environment and tested at the radial modified IEEE-34 bus system to evaluate total harmonic distortion in the current $\left(\mathrm{THD}_{\mathrm{i}}\right)$ and voltage $\left(\mathrm{THD}_{\mathrm{v}}\right)$ at PCC along with the seasonal variations. Results showed lower active, reactive, and apparent power losses of 1.9, 2.6, and $3.3 \%$, respectively, with 50\% solar PV penetration in the LV network as the voltage profile of the LV network was significantly improved compared to the base case of no solar. Further, with 50\% PV penetration, $\mathrm{THD}_{\mathrm{i}}$ and $\mathrm{THD}_{\mathrm{v}}$ at PCC were noted as 10.2 and $5.2 \%$, respectively, which is within the IEEE benchmarks at LV.
\end{abstract}

Keywords: photovoltaics (PV) system; single-phase system; nonlinear loads; point of common coupling (PCC); total harmonic distortion (THD); power losses

\section{Introduction}

Grid-connected photovoltaic (PV) systems have become a viable option in low-voltage (LV) networks due to the introduction of lucrative policy frameworks such as metering and significant cost reduction in PV system installation [1-3]. Consequently, a large amount of rooftop solar PV is expected to be connected to utility grids in coming years. A considerable amount of solar PV is already connected to weak grids; this large penetration of rooftop solar PV at the LV distribution grid has a significant effect on harmonic pollution levels in the network. Power quality issues related to the low power factor of nonlinear loads and high harmonic current emissions from solar PV inverters at the LV network greatly affect the network performance. The power electronic converters/inverters that do not produce pure sinewaves introduce harmonics into the system when connected to the LV grid. From the perspective of power quality, it is desirable that a pure sinusoidal waveform of current is obtained at the output of the grid-connected PV inverter. However, due to the presence of power electronic inverters, harmonics may arise at the output of the inverter and travel through the impedance of the distribution system, resulting in distortion of the sinusoidal voltage waveform of the utility grid. Maximum power point tracking (MPPT), anti-islanding, grid fault conditions, and energy measurement are important characteristics 
of any grid-connected PV inverter [4]. Usually, grid-connected residential PV systems have small to medium sizes ( 1 to $15 \mathrm{~kW}_{\mathrm{p}}$ ) compared to the high short-circuit levels of the distribution grid. Therefore, distortion in system voltage is almost negligible when a single PV system is connected to the grid. However, when multiple connections are made at the same feeder or distribution grid, it may affect the system voltage at the point of common coupling (PCC). For instance, in Lahore, Pakistan, residential prosumers with three-phase net meters can install rooftop solar PV up to $1 \mathrm{MW}_{\mathrm{p}}$. For sustainable operation of the power system, harmonic analysis facilitates the integration of grid-connected solar $\mathrm{PV}$ into the system. To gauge the harmonic impacts triggered by grid-connected solar PV systems, several studies have been performed over the past few years [5-19]. For example, Ref. [5] studied the harmonic compensation feature provided by prosumer PV systems as a way to improve the voltage profile. The authors of [6] analyzed harmonic emissions from PV inverters while varying the solar irradiance levels and compared the results with field measurements. Elkholy et al. [7] investigated the field measurements of power quality parameters on an $8 \mathrm{~kW}_{\mathrm{p}} \mathrm{PV}$ system connected to a low-voltage grid and presented a relationship between voltage and current harmonics in a LV system. Eltawil et al. [8] found that inverter failures are the most frequent incidents in grid-connected PV systems. The authors recommended that PV inverters should be operated at unity power factor rather than variable power factor. The authors of [9] investigated the impact of grid-connected PV during low current flows. High values of total harmonic distortion in the current $\left(\mathrm{THD}_{\mathrm{i}}\right)$ were observed for a small-scale PV system installed on a rooftop in Egypt. The authors of [11] presented a harmonic distortion Norton equivalent model for single-phase and three-phase grid-connected PV systems. Patsalides et al. [12] observed that the power quality of busbars inside the distribution network decreased after installing higher concentration of rooftop PV systems. Pereira et al. [13] analyzed the use of the current impedance model to predict harmonic current emission from grid-tied inverters. The authors of [14] presented power quality (PQ) (active and reactive power) analysis for a real rural grid-connected PV system. Increased voltage pollution was observed near the injection point, leading to decreased voltage PQ. Sakar et al. [15] determined the maximum penetration level of PV systems considering bus voltage root mean square (RMS) limits and the current-carrying capability of supply lines. The authors of [18] investigated the influence of high penetration of three-phase and single-phase rooftop PV systems by considering the individual as well as total generation capacity inside the grid. In $[16,17,19]$, the behavior of practical rooftop grid-connected PV systems in Brazilian, Croatian, and Australian distribution networks, respectively, were examined.

Harmonics are also introduced by the presence of nonlinear loads and switching devices connected to the grid. Residential nonlinear loads generally comprise devices such as transformers, compact fluorescent lamps (CFL), light-emitting diodes (LED), fluorescent tubes, air conditioners, inverters, mobile chargers, switch-mode power supplies (SMPS), $\mathrm{TV}$, computers, and laptop chargers. SMPS are commonly present in laptops, computers, $\mathrm{TV}$, and battery chargers for mobile phones. Globally, nonlinear loads in residential settings make up $38-42 \%$ of the utility loads, while lighting loads vary from 40 to $70 \%$. Nonlinear loads, when supplied with sinusoidal voltage sources, produce harmonics in the supply waveform and consequently affect the operation of other linear devices connected to the distribution grid. Various studies have investigated the harmonic effects of nonlinear loads on the distribution grid [20-32]. A novel scheme for mitigating harmonic problems caused by LV devices in residential distribution systems was presented in [20]. The authors of [21] investigated the electrical performance (harmonic voltage levels) of a range of modern domestic appliances and their potential impact on the LV distribution network. McLorn et al. [22] presented a method for characterizing the active power, reactive power, and harmonic current distortion characteristics of selected types of modern lighting. The authors of [23-26] investigated and compared the $\mathrm{THD}_{\mathrm{i}}$ and total harmonic distortion in the voltage $\left(\mathrm{THD}_{\mathrm{v}}\right)$ of various home appliances in the residential grid. In [27], a harmonic coupled matrix model was proposed based on the measured data of nonlinear home 
appliances. In [28-30], the authors established that harmonic currents in a network depend on the emission characteristics of connected devices, their phase angles, and the distortion levels of the supply voltage. Piccirilli et al. [31] considered the current distortion produced by Class-D full-wave rectifier to transfer wireless power. Corti et al. [32] proposed a precise methodology for DC-DC converter simulation while considering the nonlinear and dynamic nature of the photovoltaic device. A few studies have also characterized the combined impact of grid-connected solar PV along with the consideration of a few nonlinear loads [33,34].

However, none of the aforementioned studies characterized the potential harmonic impacts of grid-connected rooftop solar PV in the presence of diverse nonlinear load profiles of residential devices. In this study, the load data (nonlinear load penetration levels and $\mathrm{THD}_{\mathrm{i}}$ ) from a practical feeder in Lahore, Pakistan, was used as an example and tested on a modified IEEE-34 bus system. The utility, Lahore Electric Supply Company (LESCO), allows residential customers with three-phase meters to install net metering (rooftop solar PV). Therefore, in this work, we investigated the different levels of THD produced at PCC in the LV network under varying penetrations of three-phase solar PV along with the existence of balanced single-phase household nonlinear loads. Various regulatory requirements and standards exist for grid-connected PV systems in terms of voltage and current distortions due to the presence of harmonics at PCC, such as IEEE Std 519, IEEE Std P519a, ANSI C82.11, ANSI C82.14, and EN50160 [35]. However, in this work, IEEE 519-2014 standard was used as a reference for current distortion limits in the distribution grid rated from $120 \mathrm{~V}$ through to $69 \mathrm{kV}$ as listed in Table 1 [36]. It shows the maximum harmonic current distortion in $I_{s c}$ (short circuit current) and $I_{L}$ (full load current) for odd harmonics. Even harmonics are limited to $25 \%$ of the odd harmonic limits (and can therefore be neglected). The short-circuit current $\left(I_{s c}\right)$ in $\mathrm{kA}$ of a distribution transformer can be calculated using (1).

$$
I_{s c}=\frac{S_{\text {base }} \times 100}{\sqrt{3} \times V_{\text {base }} \times Z \%}
$$

where $S_{\text {base }}$ represents the transformer rating in $\mathrm{kVA}, V_{\text {base }}$ shows the voltage rating of secondary in volts $(\mathrm{kV})$, and $Z \%$ is the per unit of the transformer (in \%). Additionally, the $\mathrm{THD}_{\mathrm{v}}(\%)$ limits according to IEEE 519-2014 standards for different bus voltages at PCC are given in Table 2 [36].

Table 1. Current distortion limits for distributed system rated below $69 \mathrm{kV}$ [36].

\begin{tabular}{|c|c|c|c|c|c|c|}
\hline $\mathrm{Isc} / \mathrm{I}_{\mathrm{L}}$ & $3 \leq h<11$ & $\mathbf{1 1} \leq \mathrm{h}<\mathbf{1 7}$ & $17 \leq \mathrm{h}<23$ & $23 \leq \mathbf{h}<35$ & $35 \leq h<50$ & $\begin{array}{c}\text { Total Harmonic } \\
\text { Distortion, THD (\%) }\end{array}$ \\
\hline$<20$ & 4 & 2 & 1.5 & 0.6 & 0.3 & 5 \\
\hline $20<50$ & 7 & 3.5 & 2.5 & 1 & 0.5 & 8 \\
\hline $50<100$ & 10 & 4.5 & 4 & 1.5 & 0.7 & 12 \\
\hline $100<1000$ & 12 & 5.5 & 5 & 2 & 1 & 15 \\
\hline$>1000$ & 15 & 7.0 & 6 & 2.5 & 1.4 & 20 \\
\hline
\end{tabular}

Table 2. Voltage distortion limits at the point of common coupling (PCC) for the distribution feeder as per IEEE standards [36].

\begin{tabular}{cc}
\hline Bus Voltage at PCC & Total Harmonic Distortion, THD (\%) \\
\hline $\mathrm{V} \leq 1.0 \mathrm{kV}$ & 8 \\
\hline $1 \mathrm{kV}<\mathrm{V} \leq 69 \mathrm{kV}$ & 5 \\
\hline $69 \mathrm{kV}<\mathrm{V} \leq 161 \mathrm{kV}$ & 2.5 \\
\hline $161 \mathrm{kV}<\mathrm{V}$ & 1.5 \\
\hline
\end{tabular}


The rest of the paper is organized as follows: Section 2 describes the phenomenon of harmonics as a power quality parameter to gauge the stability of the LV network. The harmonic current emissions from individual household nonlinear loads and rooftop solar $\mathrm{PV}$ at the distribution grid are also discussed in Section 2. Section 3 presents the different simulation scenarios and cases to measure THD at PCC. An optimal sitting of distributed generators (solar PVs) is discussed that meets IEEE and IEC standards. A summary of findings from the study and future research directions are discussed in Section 4.

\section{Methodology}

The total harmonics ratio to the fundamental frequency component is defined as the THD of the system. The root mean square voltage and current at the output of PV inverter or supplying a nonlinear load is given as (2) and (3), respectively.

$$
\begin{gathered}
V_{r m s}=\frac{\sqrt{V_{1}^{2}+V_{2}^{2}+V_{3}^{2}+\ldots+V_{h_{\max }}{ }^{2}}}{\sqrt{2}} \\
I_{r m s}=\frac{\sqrt{I_{1}^{2}+I_{2}^{2}+I_{3}^{2}+\ldots+I_{h_{\max }} 2}}{\sqrt{2}}
\end{gathered}
$$

where $V_{1}, V_{2}, \ldots, V_{h_{\max }}$ and $I_{1}, I_{2}, \ldots, I_{h_{\max }}$ refer to the peak values of fundamental, second-order, and higher-order harmonics of voltage and current waveform, respectively. $\mathrm{THD}_{\mathrm{v}}$ and $\mathrm{THD}_{\mathrm{i}}$ refers to the total harmonic distortion in the voltage and current waveforms given by (4) and (5), respectively.

$$
\begin{aligned}
T H D_{v} & =\frac{\sqrt{V_{2, r m s}^{2}+V_{3, r m s}^{2}+V_{4, r m s}^{2}+\ldots+V_{h_{\max }, r m s}{ }^{2}}}{V_{1, r m s}} \\
T H D_{i} & =\frac{\sqrt{I_{2, r m s}^{2}+I_{3, r m s}^{2}+I_{4, r m s}{ }^{2}+\ldots+I_{h_{m a x}, r m s}{ }^{2}}}{I_{1, r m s}}
\end{aligned}
$$

The distortion in the voltage or current waveform at the output of PV inverter or when supplying a nonlinear load is known as the distortion factor (DF), given by (6). When supply voltage and current are not in-phase with each other, they are represented by displacement power factor (DPF), expressed as (7).

$$
\begin{gathered}
D F=\sqrt{\frac{1}{\left(1+(T H D)^{2}\right.}}=\frac{I_{1, r m s}}{I_{r m s}} \\
D P F=\frac{\frac{\sum_{i=1,2,3, \ldots}^{T}\left(I_{i} * V_{i}\right)}{T}}{V_{r m s} * I_{r m s}}=\cos \varnothing
\end{gathered}
$$

where $I_{i}$ and $V_{i}$ refer to the instantaneous values of current and voltage, respectively. Here, $\varnothing$ is the angle between the voltage and current signals. As per IEEE Standard 1459-2014, the power factor for any nonlinear load is described as the product of DF and DPF given by (8).

$$
P F=D F * D P F=\sqrt{\frac{1}{\left(1+(T H D)^{2}\right.}} * \cos \varnothing .
$$

For linear loads, DF is zero due to the nonpresence of harmonics in the supply waveforms of voltage and current, and the displacement power factor is equivalent to apparent power factor. However, in the presence of nonlinear loads, DF is nonzero, and the reactive power $(Q)$ can be calculated using $(9)$.

$$
Q=P * \tan \left(\left(\cos ^{-1} P F\right)\right)
$$


where $P$ is the active power (W), and PF is the power factor of any load. Any nonlinear load with higher values of $\mathrm{THD}_{\mathrm{i}}$ will result in lower values of $\mathrm{PF}$, as observed from Equation (7). Correspondingly, lower values of PF will result in higher amounts of reactive power demand from the distribution grid by nonlinear loads. Hence, household appliances with a higher amount of harmonic pollution will demand a higher percentage of reactive power from the grid (low power factor). As a result, these appliances deteriorate the power quality of the low-voltage distribution network with higher demands of reactive as well as apparent power. After the presence of harmonics, the expression for apparent power at any particular bus/node of a distribution feeder can be expressed as (10).

$$
S=\sqrt{P^{2}+Q^{2}+D^{2}}
$$

where $D$ represents the current distortion power stated as (11).

$$
D=\sum_{h=2}^{n} V_{1} * I_{h}(\text { var })
$$

Here, $V_{1}$ and $I_{h}$ signify the RMS values of fundamental voltage and current of harmonic order $h$ to order $n$, respectively. In this study, as discussed in the earlier section, a typical feeder of LESCO was taken as an example to help evaluate the $\mathrm{THD}_{\mathrm{v}}$ and $\mathrm{THD}_{\mathrm{i}}$ levels injected at a LV network in the presence of nonlinear residential loads along with grid-connected rooftop solar PV generation (net metering). The average distribution (\%) of electricity consumption for a typical household in Lahore is characterized in Figure 1 [37]. Additionally, typical values of $\mathrm{THD}_{\mathrm{i}}$ for various household appliances of a typical feeder in Lahore, along with the respective power factors and power ratings, are presented in Table 3 [37].

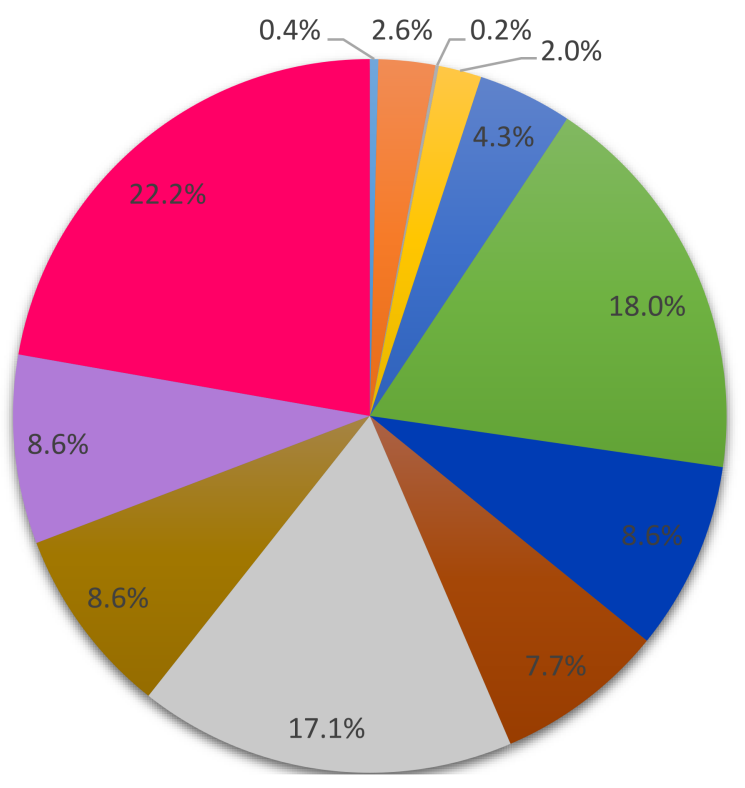

$$
\begin{aligned}
& \text { - Laptop Charger } \\
& \text { - LED/LCD/TV } \\
& \text { - Mobile Charger } \\
& \text { 口 CFL } \\
& \text { - Microwave Oven } \\
& \text { - Refrigerator } \\
& \text { - Washing Machine } \\
& \text { - Fan } \\
& \text { Water Dispenser } \\
& \text { - Electric Kettle } \\
& \text { - Electric Heater } \\
& \text { - Air Conditioner }
\end{aligned}
$$

Figure 1. The distribution of electricity consumption for a typical (average) household in Lahore, Pakistan. 
Table 3. Power rating (W), total harmonic distortion in the current $\left(\mathrm{THD}_{\mathrm{i}}\right.$ in $\%$ ), and power factor of household appliances connected with the Lahore Electric Supply Company (LESCO) feeder [37].

\begin{tabular}{ccccc}
\hline $\begin{array}{c}\text { Household } \\
\text { Appliances }\end{array}$ & $\begin{array}{c}\text { Power Rating } \\
\text { (Watt) }\end{array}$ & THD $\mathbf{i}(\mathbf{)})^{\text {Power Factor }}$ & $\begin{array}{c}\text { Fundamental } \\
\text { (PF) }\end{array}$ & $\begin{array}{c}\text { Current, } \mathbf{~}_{\mathbf{1}} \\
\text { (A)(RMS) }\end{array}$ \\
\hline Laptop charger & 45 & 148.76 & 0.57 & 0.34 \\
\hline LED/LCD/TV & 30 & 139.12 & 0.56 & 0.23 \\
\hline Mobile charger & 6 & 138.04 & 0.48 & 0.054 \\
\hline CFL & 24 & 100.96 & 0.67 & 0.15 \\
\hline $\begin{array}{c}\text { Microwave } \\
\text { Oven }\end{array}$ & 1000 & 19.48 & 0.97 & 1.22 \\
\hline Refrigerator & 150 & 17.1 & 0.53 & 2.18 \\
\hline $\begin{array}{c}\text { Washing } \\
\text { machine }\end{array}$ & 500 & 11.63 & 0.99 & 0.49 \\
\hline Fan & 100 & 6.14 & 0.87 & 2.18 \\
\hline Water dispenser & 500 & 2.24 & 0.99 & 4.46 \\
\hline Electric kettle & 1000 & 1.89 & 0.97 & 4.37 \\
\hline Electric heater & 1000 & 1.87 & 0.99 & 5.92 \\
\hline Air conditioner & 1300 & 50 & 0.95 & \\
\hline
\end{tabular}

Moreover, in addition to nonlinear loads, nonlinearity in the distribution grid can be introduced by distributing harmonic sources such as non-sinusoidal waves at the output of solar PV inverters. As it stands, generally, inverters need to come with high-quality switching, producing pure sinusoidal waves. However, mostly modified sine waves of current and voltage at the output of substandard inverters pollute the LV grid. Therefore, net metering prosumers must insert the required reactive power along with the active power into the grid. However, residential customers do not meet the standard criterion of delivering the reactive power. Consequently, capacitor banks or synchronous condensers are required to be installed by the utility for power factor correction at the LV grid. Therefore, to accurately model and benchmark the harmonic pollution that can be produced due to the insertion of solar PV inverters, a real solar PV module along with the typical harmonic spectrum at the output of the inverter was used in this study. The specific parameters such as power rating $(\mathrm{W})$, open-circuit voltage $\left(V_{o c}\right)$, short-circuit current $\left(I_{s c}\right)$, and efficiency $(\eta)$ of the solar PV module considered in the simulations at standard testing conditions (STC) are given in Table 4 along with the inverter specifications shown in Table 5. Further, the $I-V$ and $P-V$ curves at STC for the respective module according to the manufacturer's datasheet are shown in Figure 2.

Depending on the rooftop solar PV generation at different segments of the day and seasons of the year, distinct levels of $\mathrm{THD}_{\mathrm{i}}$ are produced at the output of the PV inverter. Therefore, based on low and high PV generation in the winter and summer seasons, the harmonic spectrum of a typical PV inverter is shown in Table 6 [17]. In addition, the $\mathrm{THD}_{\mathrm{i}}$ of the solar PV inverters with seasonal variations is given in Table 7. It can be observed from Table 7 that higher $\mathrm{THD}_{\mathrm{i}}$ is produced for the period of low generation due to higher harmonic currents of the solar PV inverter. Further, it is considered that $4 \mathrm{~kW}_{\mathrm{p}}\left(\mathrm{P}_{\mathrm{n}}\right)$ threephase solar PV system (micro distributed generation, DG) can be installed at any node of a modified IEEE-34 bus distribution network. The maximum output (at non-STC) can be 3.3 and $3.1 \mathrm{~kW}_{\mathrm{p}}$ in summer and winter, respectively. Additionally, the minimal production from solar PV during both summer and winter is taken as $0.6 \mathrm{~kW}_{\mathrm{p}}$. 
Table 4. Specification of the solar photovoltaics (PV) module parameters according to manufacturer's datasheet at standard testing conditions (STC).

\begin{tabular}{cc}
\hline Parameters & Values \\
\hline Manufacturer & Sharp \\
\hline Type & Polycrystalline \\
\hline Model & ND-224UC1 \\
\hline Power $(\mathrm{W})$ & 224 \\
\hline$V_{m p}(\mathrm{~V})$ & 29.58 \\
\hline$I_{m p}(\mathrm{~A})$ & 7.45 \\
\hline$V_{o c}(\mathrm{~V})$ & 36.44 \\
\hline$I_{s c}(\mathrm{~A})$ & 8.25 \\
\hline Efficiency $(\eta)$ & $13.7 \%$ \\
\hline Fill factor $(\mathrm{FF})$ & $73.3 \%$ \\
\hline
\end{tabular}

Table 5. Specification of the inverter used for system evaluation.

\begin{tabular}{cc}
\hline Parameters & Values \\
\hline Max. DC power $(\mathrm{kW})$ & 10 \\
\hline Rated DC voltage (V) & 1000 \\
\hline Max. input current (A) & 10 \\
\hline Max. AC apparent power (kVA) & 9 \\
\hline Rated AC voltage (V) & 400 \\
\hline Max. output current (A) & 12.9 \\
\hline Max. efficiency (\%) & 90 \\
\hline
\end{tabular}

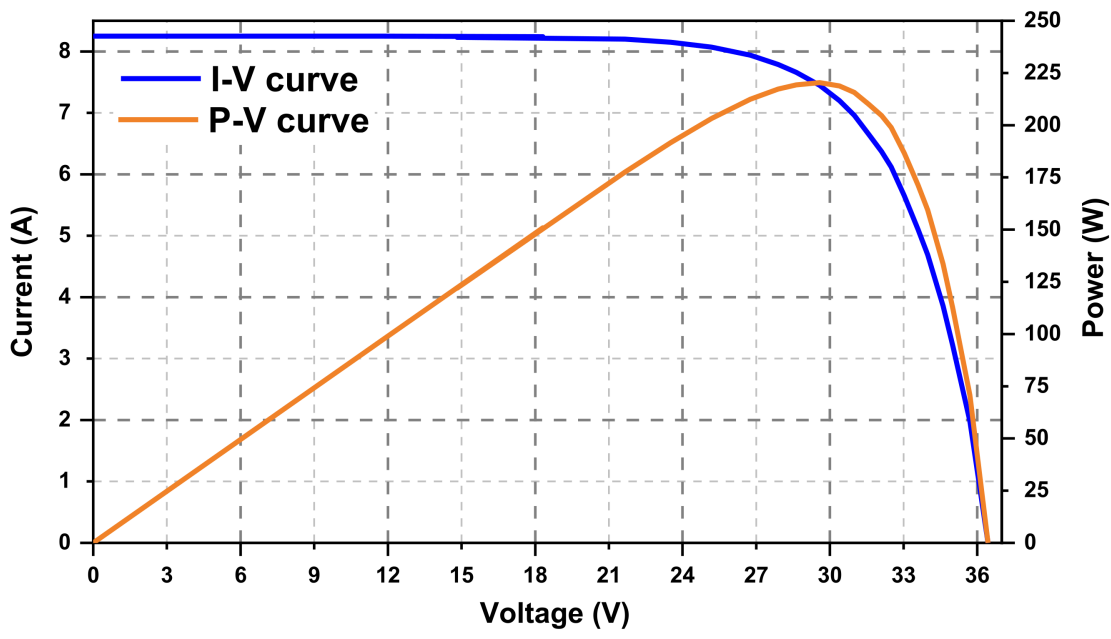

Figure 2. $I-V$ and $P-V$ curves of solar PV module at STC according to the manufacturer's datasheet. 
Table 6. Current harmonic spectrum at the output of PV inverter during different generating periods of the year [17].

\begin{tabular}{|c|c|c|c|c|}
\hline \multirow{2}{*}{$\begin{array}{c}\text { Harmonic } \\
\text { Order }\end{array}$} & \multicolumn{2}{|c|}{$I_{h}$ Relative to $I_{1}(\%)$ in Winter } & \multicolumn{2}{|c|}{$I_{h}$ Relative to $I_{1}(\%)$ in Summer } \\
\hline & $\mathrm{P} / \mathrm{P}_{\mathrm{n}}=75 \%$ & $P / P_{n}=15 \%$ & $\mathbf{P} / \mathbf{P}_{\mathbf{n}}=85 \%$ & $\mathrm{P} / \mathrm{P}_{\mathbf{n}}=15 \%$ \\
\hline 3 & 2.05 & 26.35 & 1.91 & 20.20 \\
\hline 5 & 5.82 & 30.83 & 7.20 & 25.29 \\
\hline 7 & 2.63 & 8.84 & 3.26 & 7.67 \\
\hline 9 & 0.42 & 9.92 & 0.61 & 7.64 \\
\hline 11 & 0.63 & 4.87 & 0.74 & 2.61 \\
\hline
\end{tabular}

Table 7. $\mathrm{THD}_{\mathrm{i}}(\%)$ of solar PV inverter for each scenario based on current harmonic spectrum.

\begin{tabular}{cc}
\hline Scenario & THD $_{\mathbf{i}}$ (\%) \\
\hline Summer with high overall generation (S1) & 7.8 \\
\hline Summer with low overall generation (S2) & 35.1 \\
\hline Winter with high overall generation (S3) & 7.7 \\
\hline Winter with low overall generation (S4) & 43 \\
\hline
\end{tabular}

\section{Results and Discussion}

\subsection{Cases and Scenarios}

Three cases were considered in this study along with the base case with no rooftop solar PV installed at any of the residential houses. Simulations were performed in the 20.0.0 licensed version of the electrical transient analyzer program (ETAP). Four different cases of solar PV penetration levels were taken to compare the harmonic levels inserted at PCC.
a. Base Case: $0 \%$ solar PV
b. Case 1: 33\% solar PV
c. Case 2: $50 \%$ solar PV
d. Case 3: 100\% solar PV

For cases 1-3, four different scenarios were analyzed in this study. All the cases and scenarios were tested at single radial supply modified EEE-34 bus distribution feeder. Additionally, to facilitate the benchmarking of THD limits at the LV network, high loading levels of nonlinear loads were constantly assumed at each node. Further, it was assumed that the secondary side of the distribution transformer $(11 / 0.4 \mathrm{kV})$ served as the PCC. The $\mathrm{THD}_{\mathrm{v}}$ and $\mathrm{THD}_{\mathrm{i}}$ of the system were observed as an overall index of harmonic pollution inserted into the LV network. The four scenarios considered were as follows:

1. Scenario 1 (S1): summer with high overall generation and high loading levels

2. Scenario 2 (S2): summer with low overall generation and high loading levels

3. Scenario 3 (S3): winter with high overall generation and high loading levels

4. Scenario 4 (S4): winter with low overall generation and high loading levels

\subsubsection{Base Case}

A reference case (base case) was taken to help evaluate harmonic pollution with increasing solar PV penetration. It was assumed that no solar PV system was installed at any node in the base case, as shown in Figure 3. As shown in the single line diagram (SLD) for the base case (Figure 3), each node had three single-phase connections with a cumulative balanced three-phase load of $6 \mathrm{~kW}$. The single-phase household load had nonlinear characteristics with the details presented earlier in Table 3. The modeling of a modified IEEE-34 bus distribution network composed of 34 subnetworks (buses) in ETAP is shown in Figure 4. Further, Figure 5 shows the details of each subnetwork indicating 
the types and ratings of nonlinear loads and the PV panels connected. It illustrates that for each case and scenario, the loading levels were assumed to be constant, i.e., loads remained in the ON state throughout the simulations. However, only one solar PV system out of the four types (scenarios) could be assumed to be in the ON state for a particular scenario. The rest of the three PV panels were taken to be operated in the OFF state depending on the respective scenario. In addition, depending on the specific case, it was possible that all four PV systems might operate in the disconnected mode (OFF state). For instance, each of the PV panels operated in OFF state for the base case.

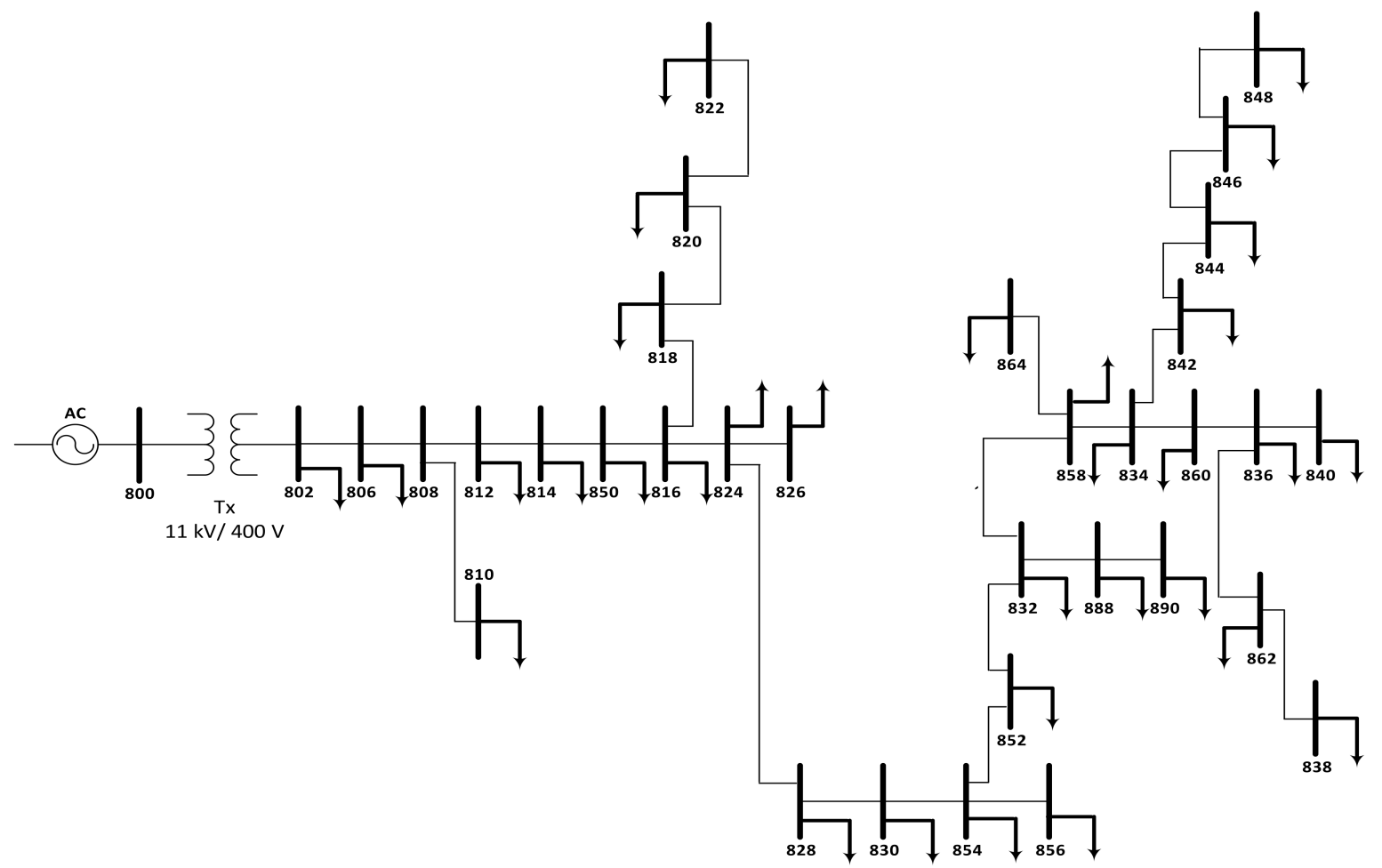

Figure 3. Single line diagram (SLD) of modified IEEE-34 bus distribution network with 0\% PV penetration.

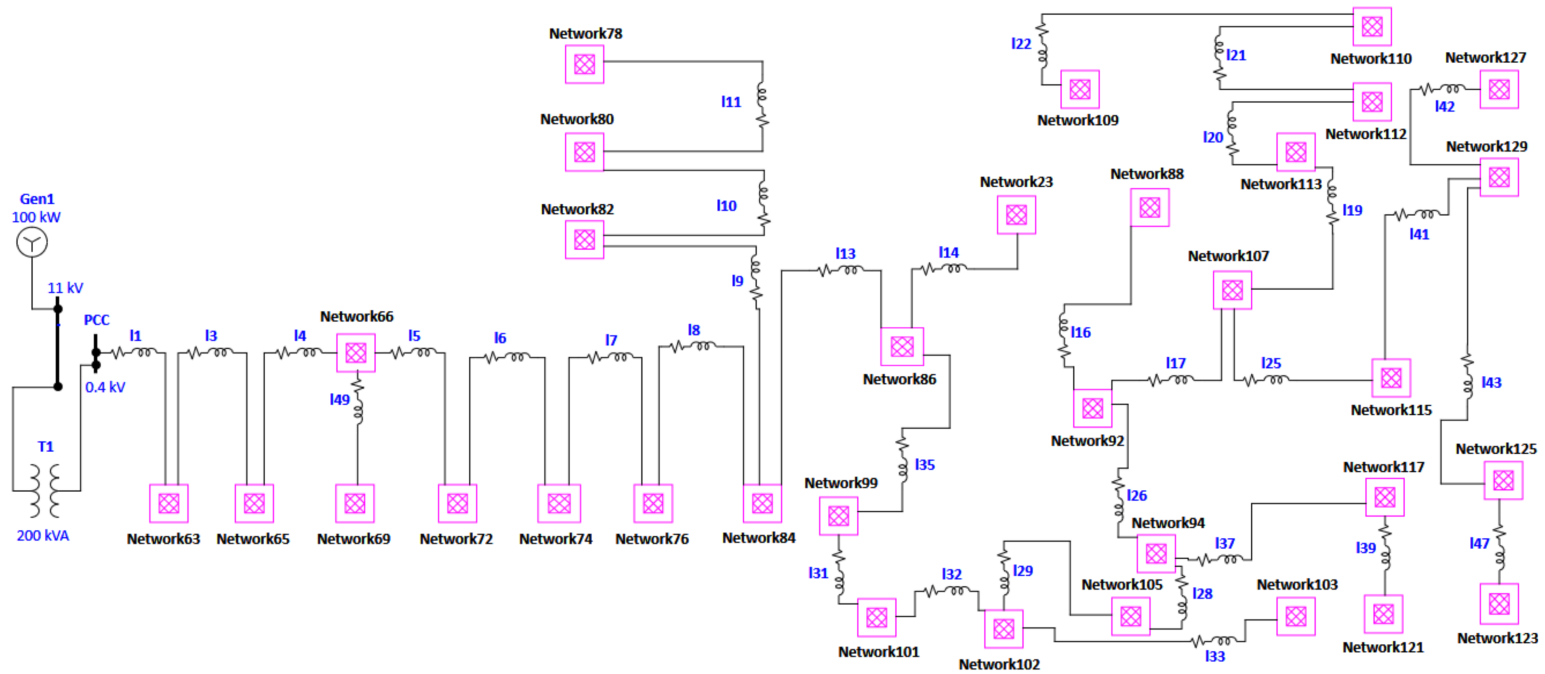

Figure 4. Modeling of modified IEEE-34 bus distribution network in electrical transient analyzer program (ETAP) 20.0.0 with 34 subnetworks (buses). 


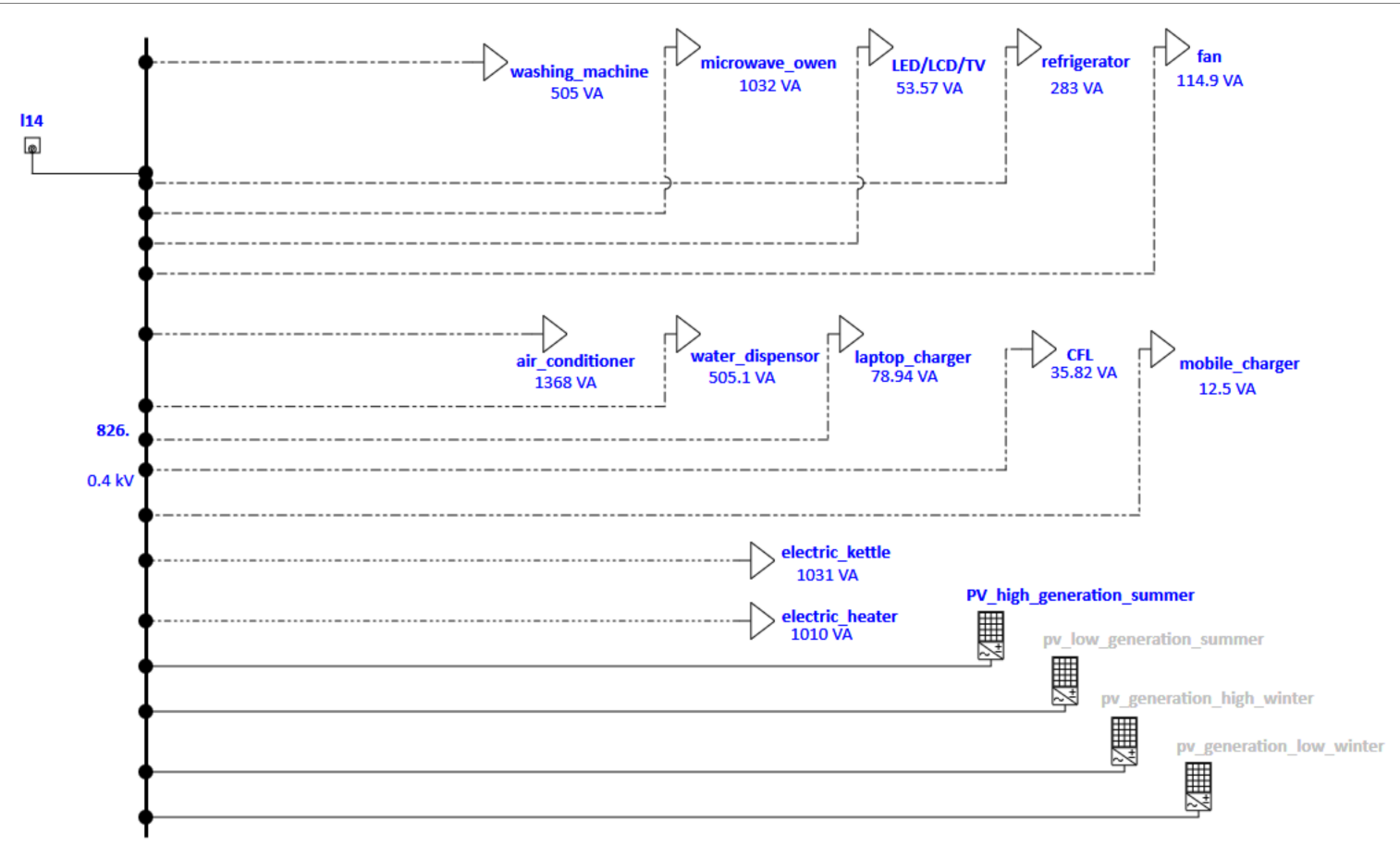

Figure 5. Details of each subnetwork in ETAP with three single-phase connections (nonlinear loads) along with the integration of PV panels.

The per unit (p.u.) voltage profile at each bus for the reference case is shown in Figure 6a. The results are plotted in the ascending order of the buses for the purpose of simplicity, but Figure 3 describes the location of the exact node. As can be seen, the buses near the distribution transformer, i.e., $802-830$, operated as marginally loaded (p.u. voltage under 0.98), whereas the buses at the far end, i.e., 832-890 except 850, were operating as critically loaded (p.u. voltage below 0.95). In addition, the voltage and current spectrum of harmonics along with $\mathrm{THD}_{\mathrm{v}}$ and $\mathrm{THD}_{\mathrm{i}}$ inserted at the PCC is shown in Figure 6b. It can be observed from the figure that the $\mathrm{THD}_{\mathrm{v}}$ level at PCC (6.6\%) was well under safe operating standards $(8.0 \%)$ when compared to the values in Table 2 . However, the $\mathrm{THD}_{\mathrm{i}}$ level at PCC $(8.8 \%)$ was marginally above the IEEE benchmark $(8.0 \%)$, as given in Table 1 , due to the high diffusion of nonlinear household loads in the network. Additionally, the voltage and current waveforms at PCC for a complete cycle is shown in Figure 6c, which shows that both the waveforms were distorted due to the high percentage of harmonic levels.

Further, the percentage of active, reactive, and complex power losses in reference to total load in the distribution network is listed in Table 8. It can be seen that reactive power losses (kVar) were almost double the active power losses $(\mathrm{kW})$ due to the poor power factor of some nonlinear devices, such as mobile and laptop chargers, CFL, LCD, refrigerator, etc. It can be observed that there was a decent margin of improving the overall voltage profile along with a reduction of complex power losses through the integration of micro distributed generation (cases 1, 2 and 3). 


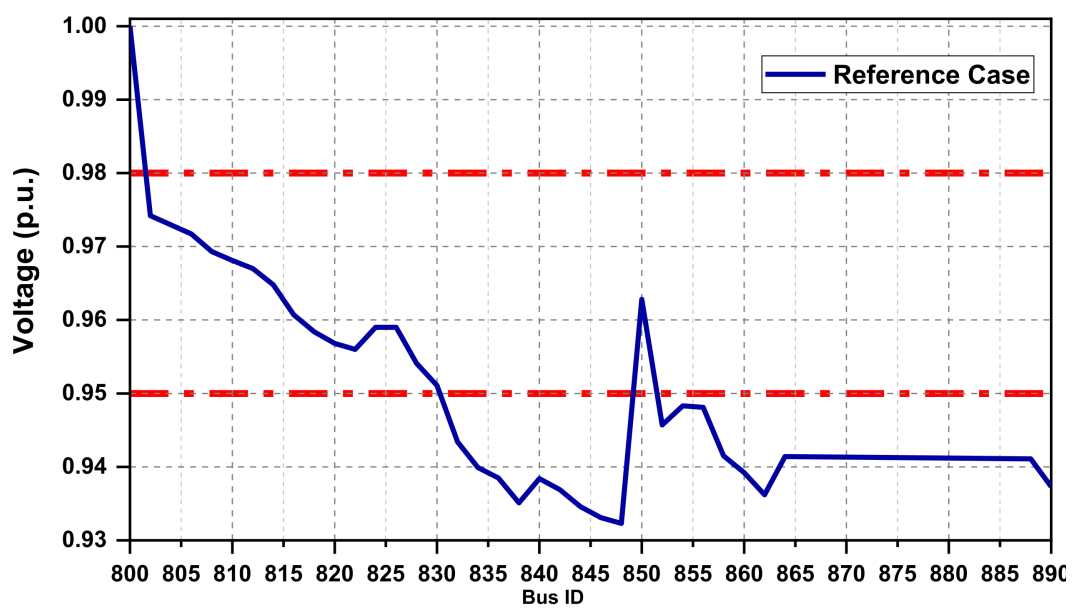

(a)

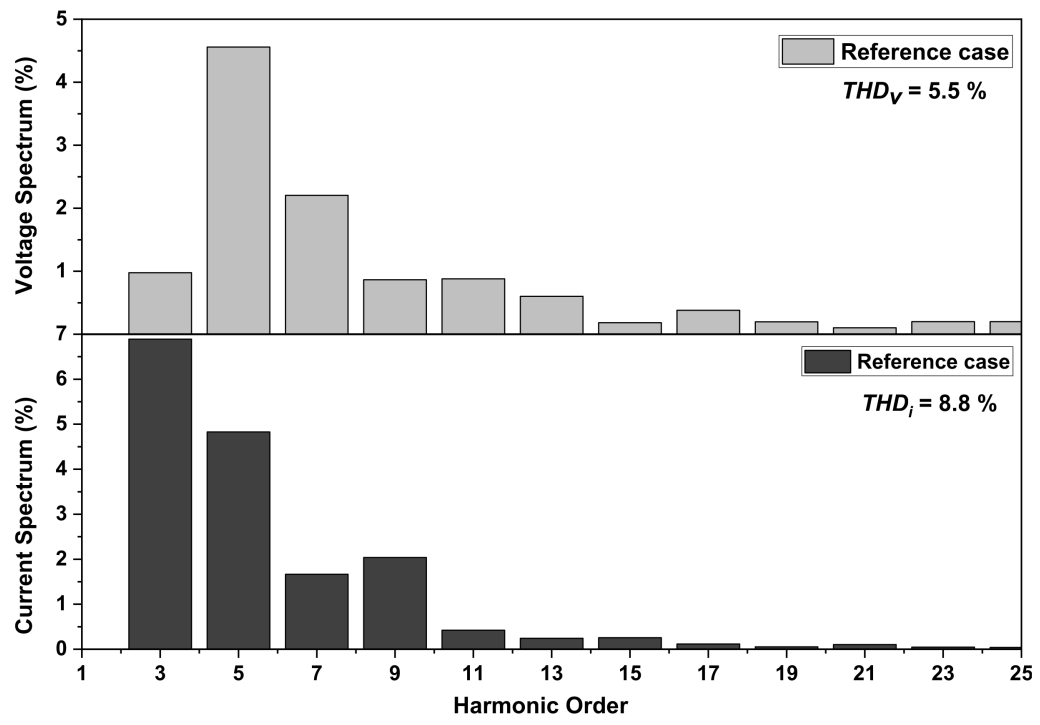

(b)

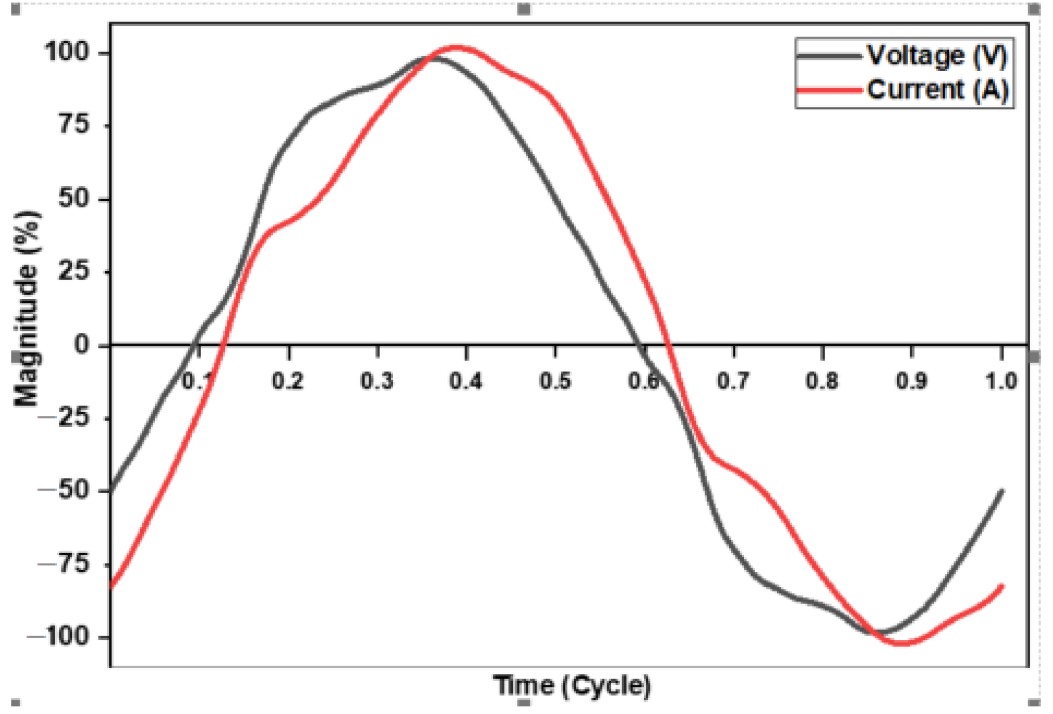

(c)

Figure 6. (a) Per unit (p.u.) voltage profile of the system, (b) voltage and current spectrum with respect to harmonic orders at PCC of modified IEEE-34 network for the reference case (without distributed generation), (c) voltage and current waveforms at PCC for a complete cycle. 
Table 8. Total active $(\mathrm{kW})$, reactive (kVar), and complex power loss (kVA) for the reference case in percentage $(\%)$ of the total load of the network (\%).

\begin{tabular}{cc}
\hline Type & Power Loss \\
\hline Active $(\mathrm{kW})$ & 3.13 \\
\hline Reactive $(\mathrm{kVar})$ & 5.8 \\
\hline Complex $(\mathrm{kVA})$ & 6.6 \\
\hline
\end{tabular}

\subsubsection{Case 1}

In this case, it was considered that $33 \%$ of the nodes were installed with rooftop solar PV, as shown in Figure 7. The SLD for case 1 (see Figure 7) showed that 12 nodes had three-phase solar PV connected (one-third of total nodes had $4 \mathrm{~kW}_{\mathrm{p}}$ solar PV system installed at each node) along with three single-phase load connections at each bus. The per unit voltage at each bus for the four scenarios of case 1 is shown in Figure 8a. It shows that for scenarios 1 and 3 (PV panels with overall high generations, i.e., 3.3 and $3.1 \mathrm{~kW}_{\mathrm{P}}$ during summer and winter, respectively), fewer buses were critically loaded (15 buses, i.e., $832-848$ and 858-890) compared to the reference case (18 buses). However, for scenarios 2 and 4 (due to an overall low generation of $0.6 \mathrm{~kW}_{\mathrm{p}}$ in both summer and winter), the voltage profiles of the buses remained fairly similar to case 0 . Figure $8 \mathrm{~b}$ shows the voltage and current waveforms at PCC for a complete cycle of case 1. Additionally, the harmonic spectrums of voltage and current at PCC for scenarios 1-4 are shown in Figure 9a,b. It shows that the total harmonic distortion $\left(\mathrm{THD}_{\mathrm{v}}\right.$ and $\left.\mathrm{THD}_{\mathrm{i}}\right)$ levels at PCC increased due to the insertion of harmonics at the output of PV inverters. The highest amount of current distortion $\left(\mathrm{THD}_{\mathrm{i}}=9.3 \%\right)$ was noted in scenario 1 with high generation during the summer season, illustrating that the current distortion increased with power production at the output of the PV inverter.

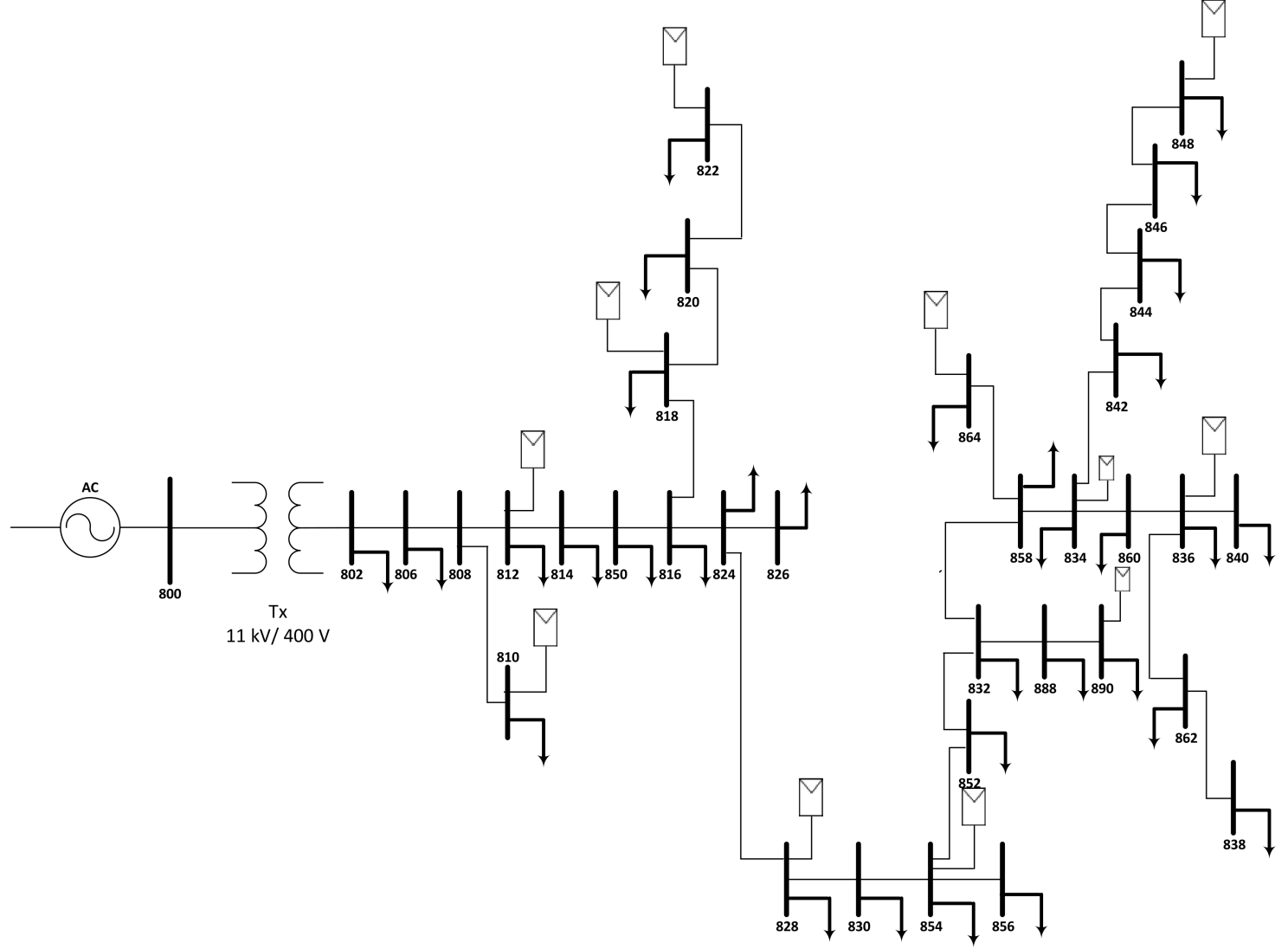

Figure 7. SLD of modified IEEE-34 bus distribution network with 33\% PV penetration. 


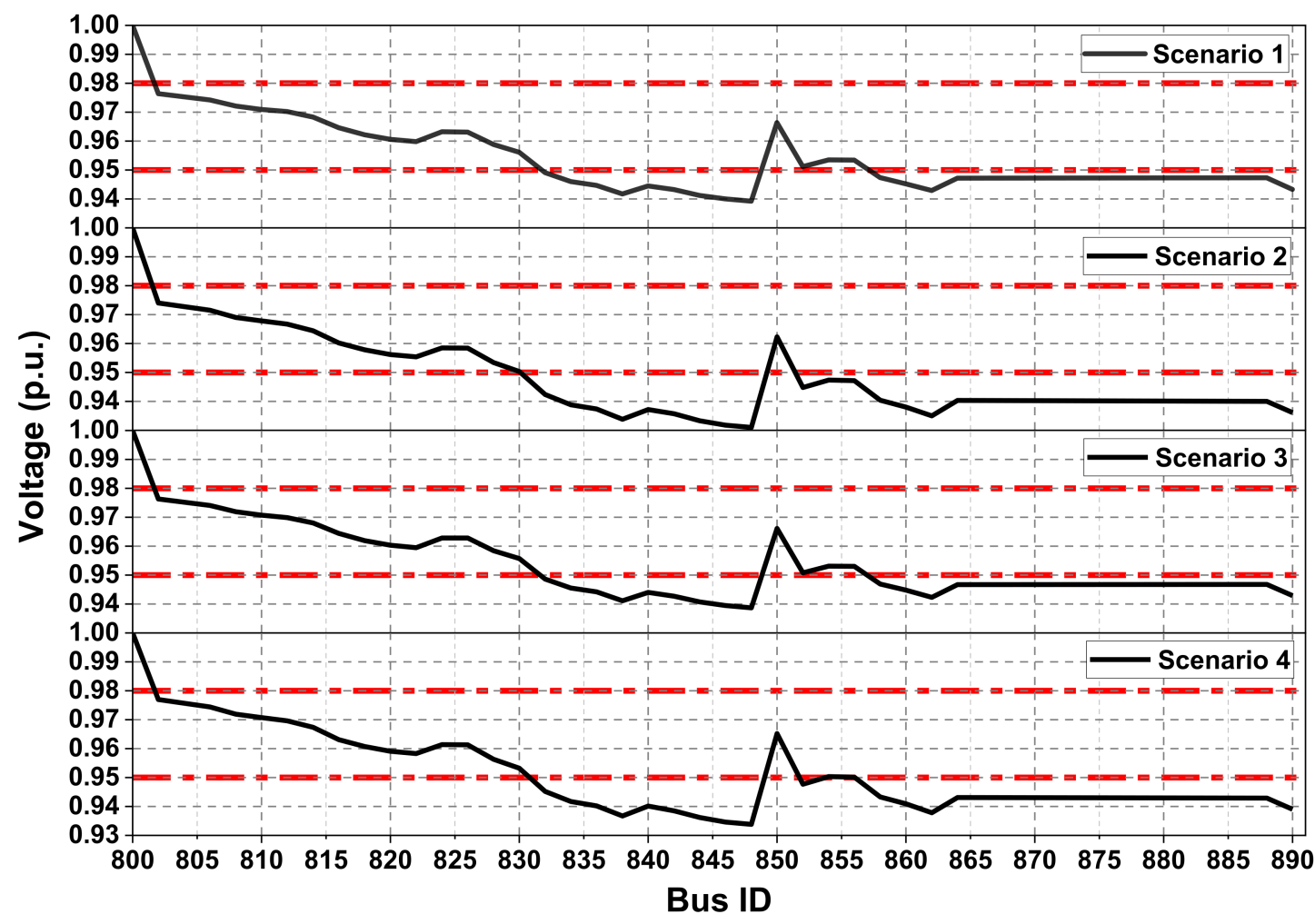

(a)
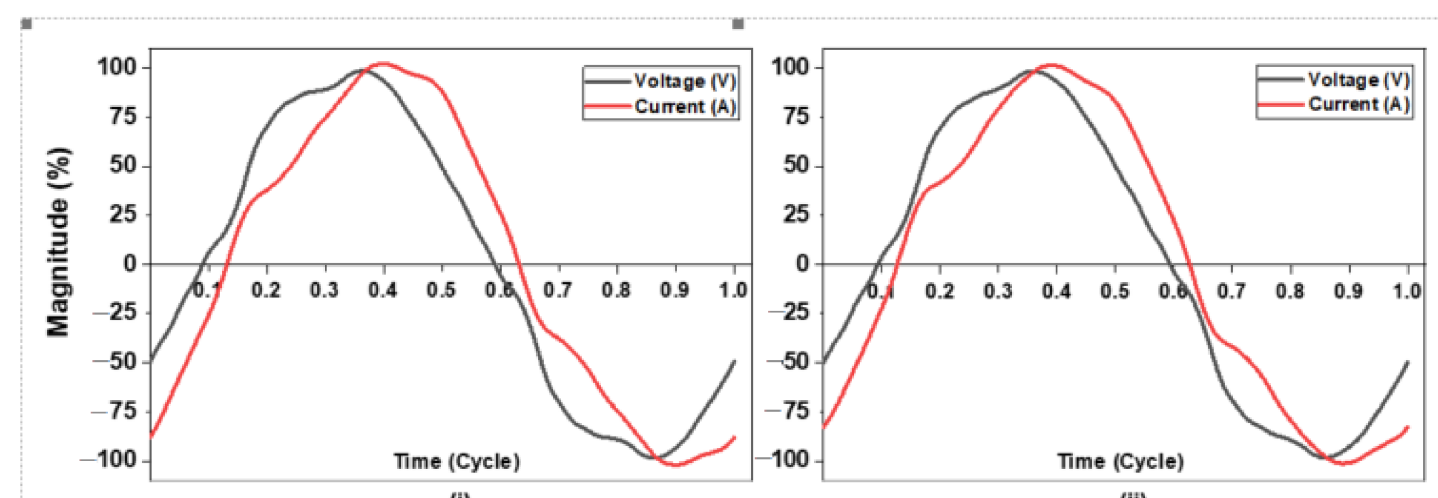

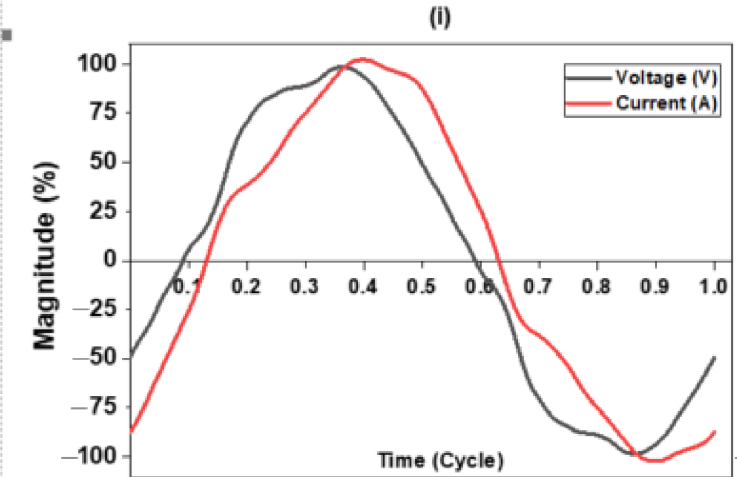

(iii)

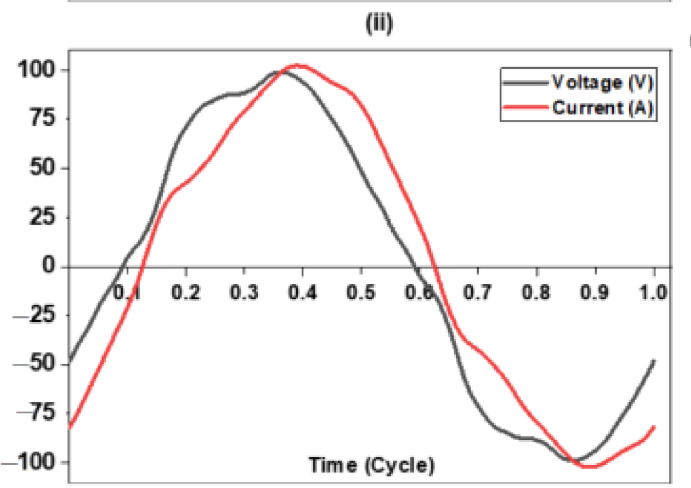

(iv)

(b)

Figure 8. (a) Per unit voltage profile along the buses for scenarios $1-4$ of case 1 (33\% PV penetration). (b) Voltage and current waveforms at PCC for a complete cycle for scenarios $1-4$ of case 1 (33\% PV penetration). 


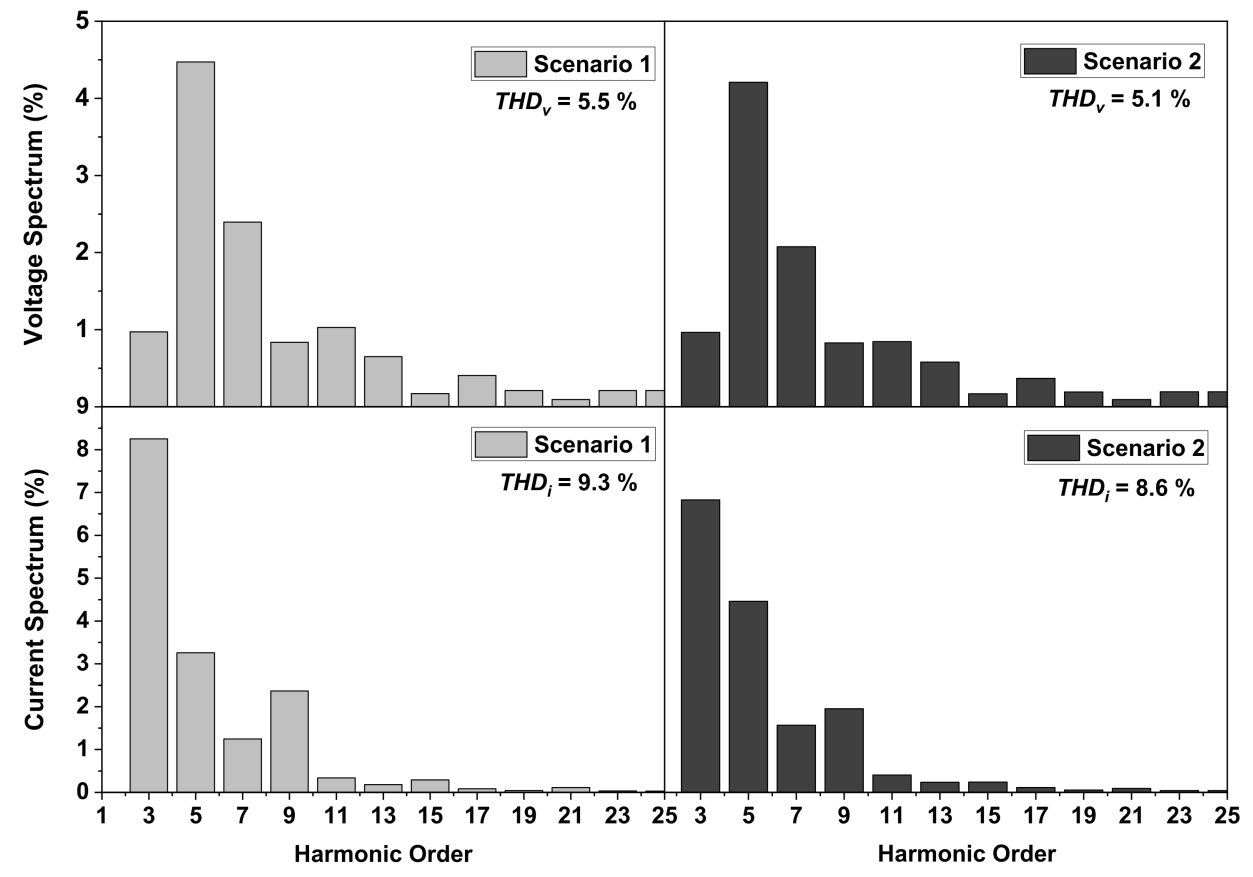

(a)

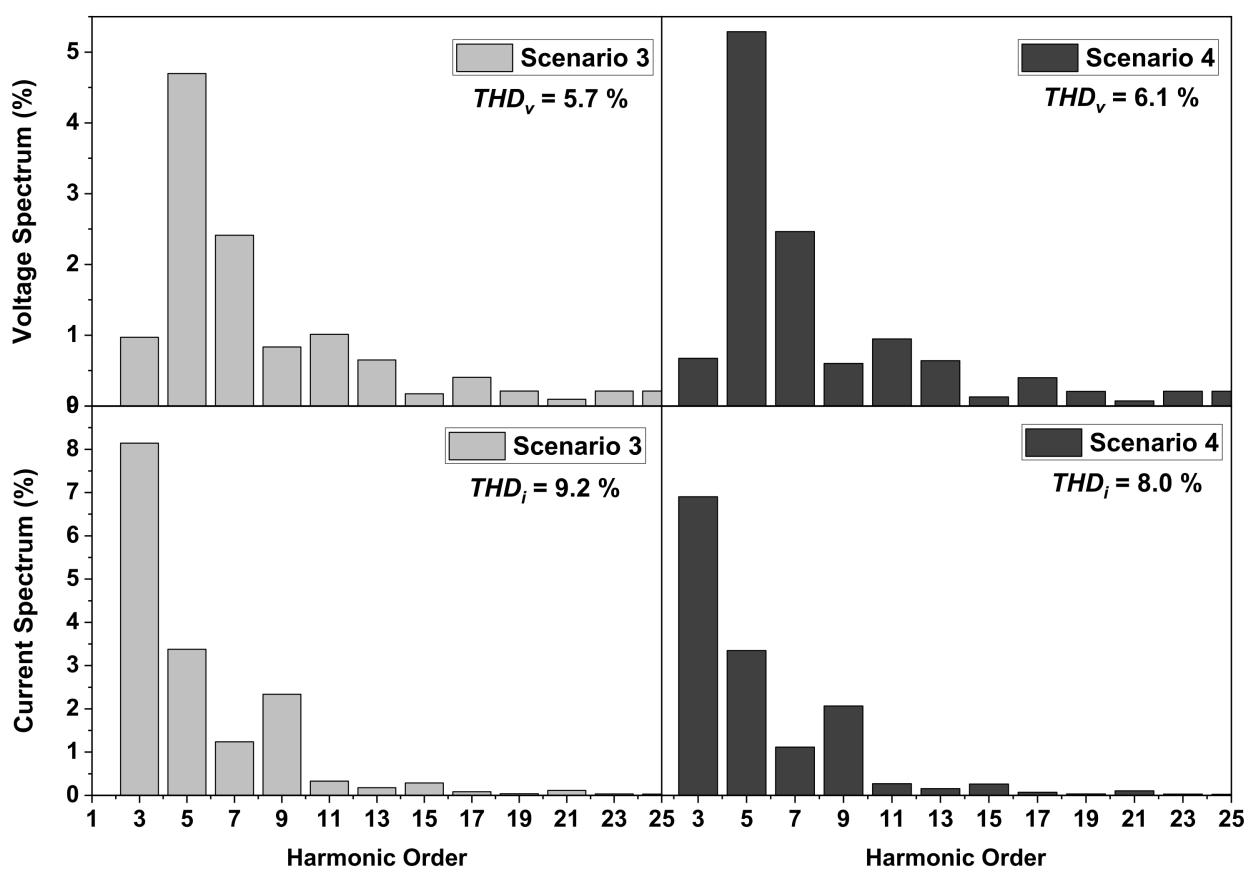

(b)

Figure 9. Voltage and current harmonic spectrum along with $\mathrm{THD}_{\mathrm{v}}$ and $\mathrm{THD}_{\mathrm{i}}$ at $\mathrm{PCC}$ for case 1 in (a) scenarios 1 and 2 and (b) scenario 3 and 4 .

\subsubsection{Case 2}

The SLD for case 2 is shown in Figure 10. It shows that $50 \%$ of the buses were connected with three-phase solar PV systems. Here, $4 \mathrm{~kW}_{\mathrm{p}}$ rooftop PV systems were installed at alternate buses along with the presence of three single-phase nonlinear household connections at each node. The per unit voltage profile of the distribution network for case 2 during four scenarios is shown in Figure 11a. As can be seen, for scenario 1 (PV panels with overall 
high generations of $3.3 \mathrm{~kW}$ at $50 \%$ buses), only four buses, i.e., 838, 844, 846, and 848, were critically loaded. Similarly, for scenario 3 ( $50 \%$ buses installed with generations of $3.1 \mathrm{~kW}_{\mathrm{P}}$ ), only five buses remained critically loaded, i.e., 838, 844, 846, 848, and 862. However, for scenarios 2 and 4, 14 buses were critically loaded while others remained marginally loaded. This can be explained by the low DG at $50 \%$ of the buses $\left(0.6 \mathrm{~kW}_{\mathrm{P}}\right)$, which resulted in more buses with critical loading. Additionally, the voltage and current waveforms for each scenario of case 2 is shown in Figure 11b. As can be seen, the highest distortion in the current and voltage waveforms was observed for scenarios 1 and 3. Further, the harmonic spectrums at PCC for scenarios 1-4 are shown in Figure 12a,b. Figure 12a shows that during summers with maximum generation, highest levels of current distortion (10.2\%) at PCC were observed due to higher harmonic currents from the PV inverter. The maximum amount of voltage distortion $(5.2 \%)$ was seen in scenario 3 with high generation $\left(3.1 \mathrm{~kW}_{\mathrm{p}}\right)$ during the winter season, as shown in Figure 12b. It can be observed that for scenario 1 , the voltage profile of the network got better as only four out of 34 buses were under critical loading conditions, with the total harmonic distortion $\left(\mathrm{THD}_{\mathrm{i}}\right.$ and $\mathrm{THD}_{\mathrm{v}}$ ) values under acceptable limits according to IEEE standards. Hence, this type of setting with solar PV generation installed at every other bus can be the optimal choice for rooftop grid-connected photovoltaic systems.

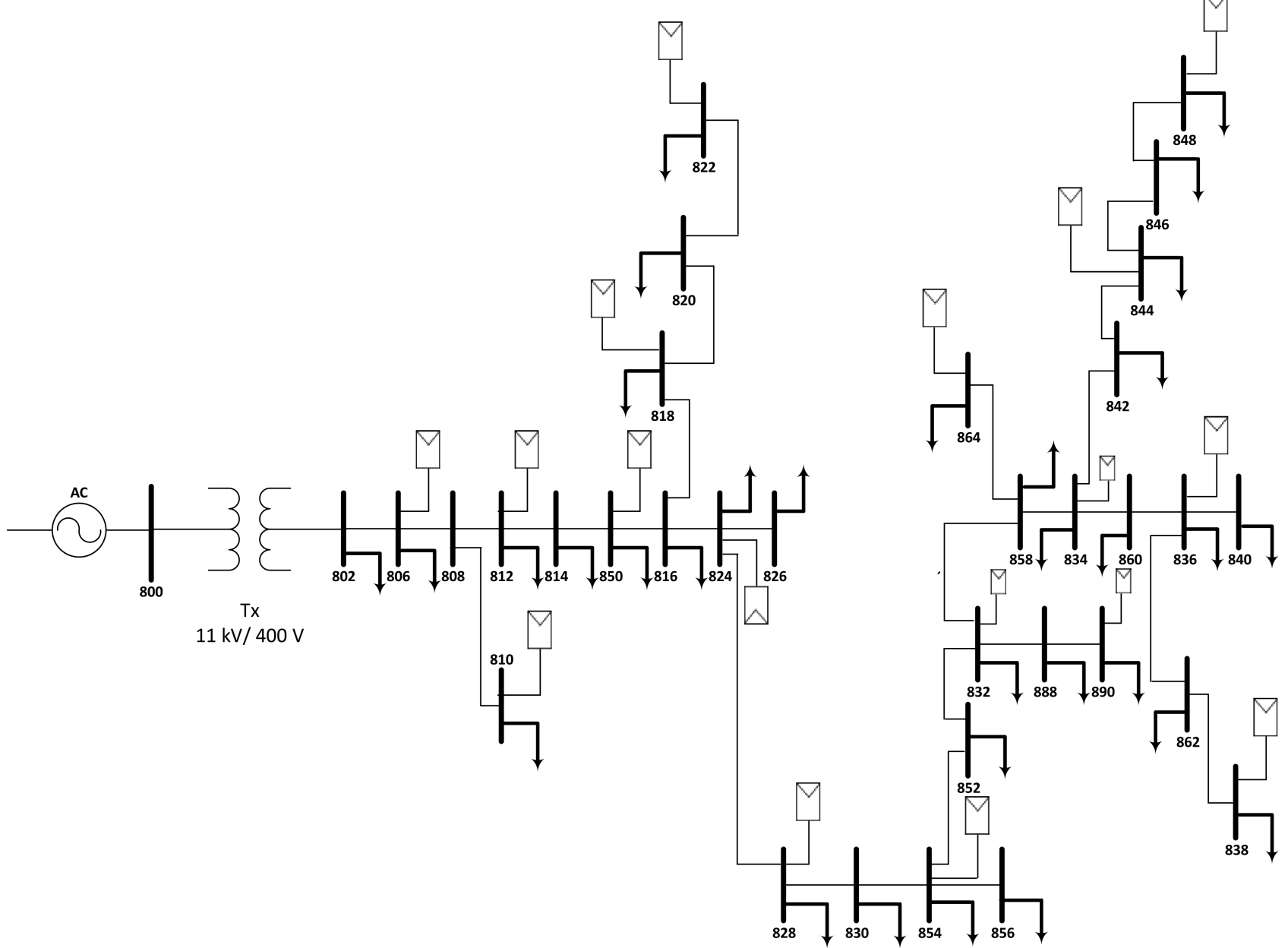

Figure 10. SLD of modified IEEE-34 bus distribution network with 50\% PV penetration. 


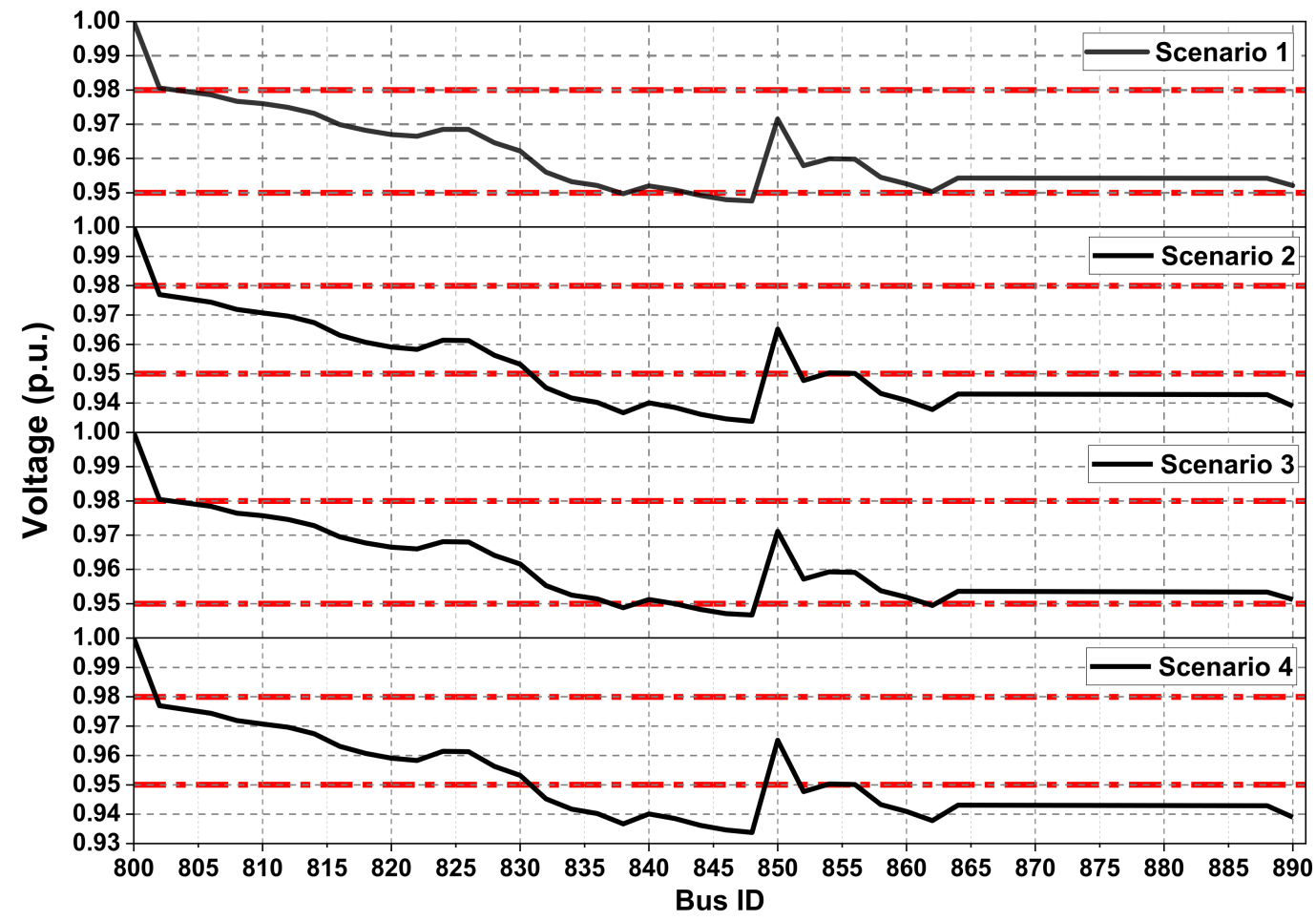

(a)

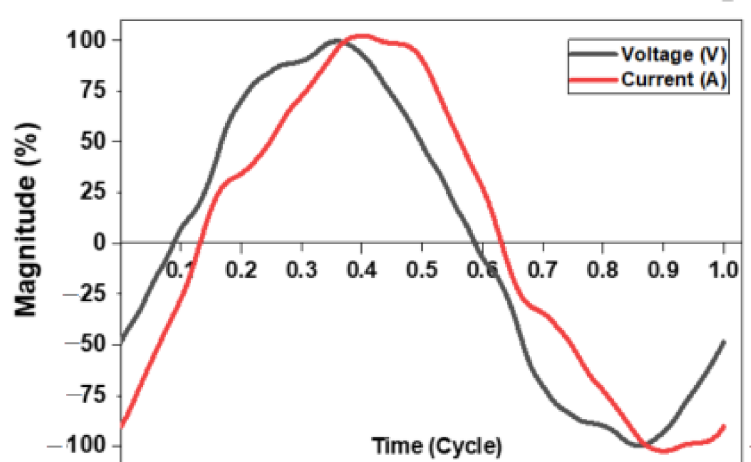

(i)

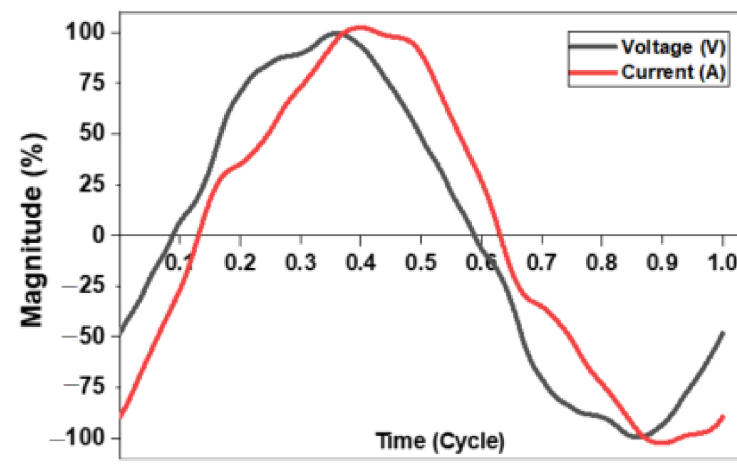

(iii)

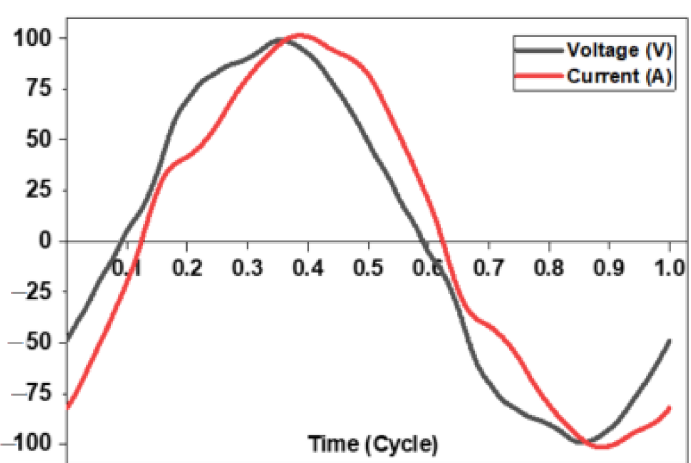

(ii)

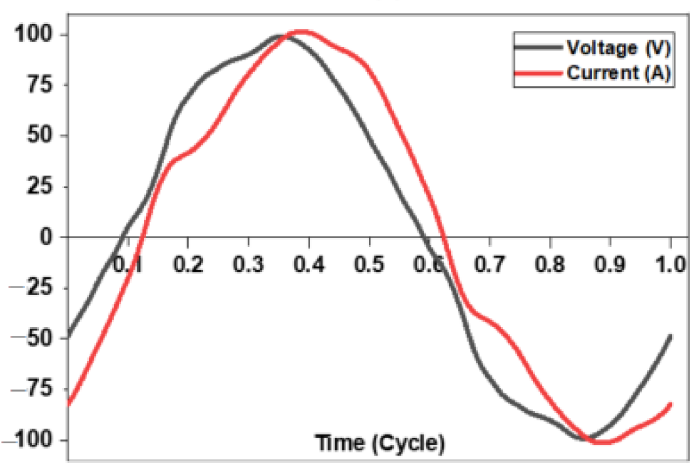

(iv)

(b)

Figure 11. (a) Per unit voltage profile of the system for scenarios $1-4$ of case 2 (50\% PV penetration). (b) Voltage and current waveforms at PCC for a complete cycle for scenarios 1-4, respectively of case 2 (50\% PV penetration). 


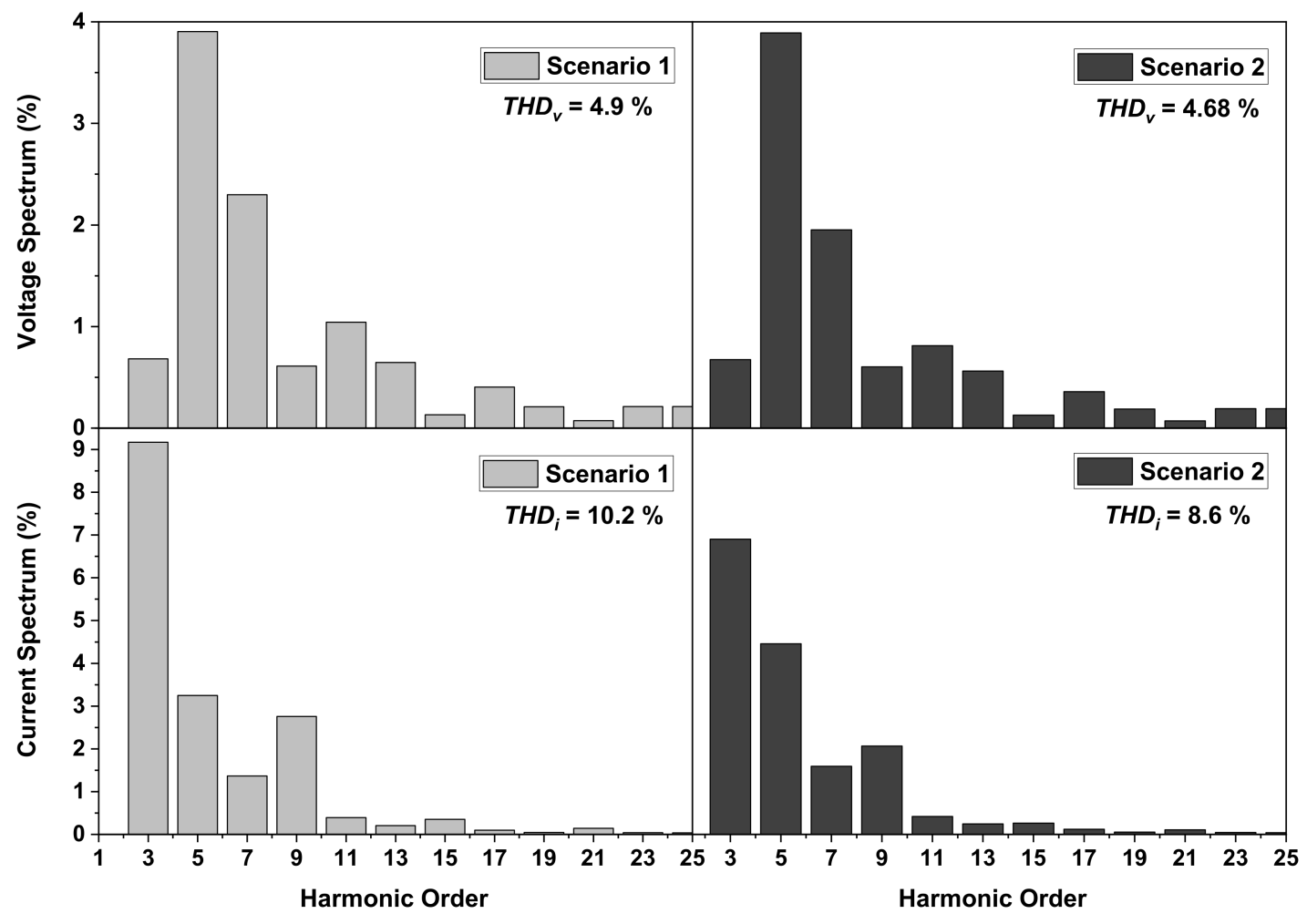

(a)

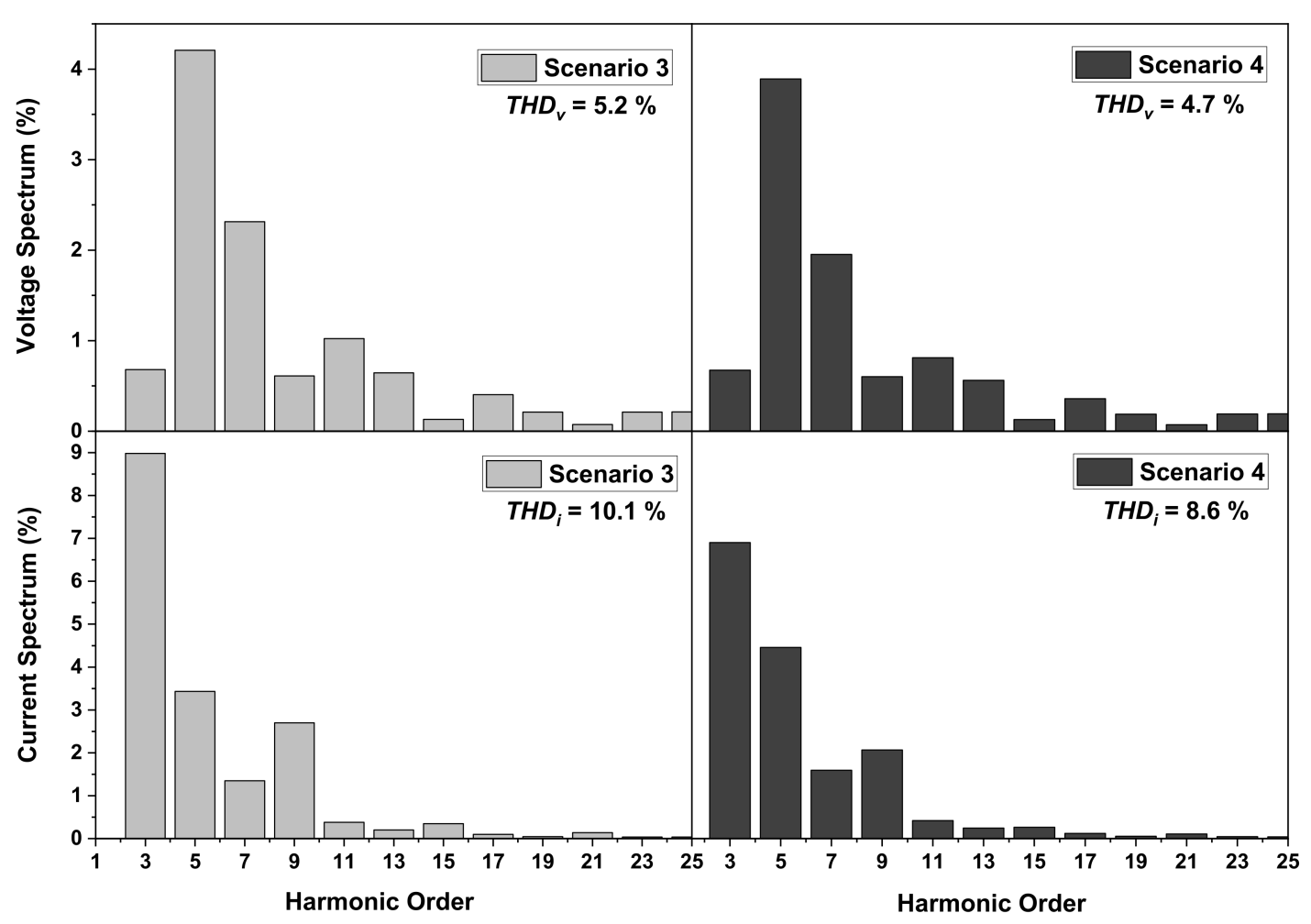

(b)

Figure 12. Voltage and current harmonic spectrum along with $\mathrm{THD}_{\mathrm{v}}$ and $\mathrm{THD}_{\mathrm{i}}$ at $\mathrm{PCC}$ for case 2 in the distribution network in (a) scenarios 1 and 2 and (b) scenarios 3 and 4 . 


\subsubsection{Case 3}

Lastly, it was considered that all buses had the deployment of $4 \mathrm{~kW}_{\mathrm{p}}$ solar PV system (case 3). The SLD for case 3, shown in Figure 13, indicated that each node had a solar PV system plus three single-phase residential connections. Hence, each node had a distributed generation of $4 \mathrm{~kW}_{\mathrm{p}}$ and a cumulative load of $6 \mathrm{~kW}$ with nonlinear characteristics. The voltage profile of the system for case 3 is shown in Figure 14a. As can be seen for scenarios 1 and 3 , none of the buses were critically loaded. In addition, a few buses adjacent to the distribution transformer, i.e., 802-810, did not operate as marginally or critically loaded; instead, the p.u. voltages were close to unity. However, during the low generation period for scenarios 2 and 4, around half of the buses (far end buses) operated in the critically loaded condition (p.u. voltage less than 0.95). In addition, the percentage magnitudes of voltage and current for a complete cycle of case 3 are shown in Figure 14b. The highest amount of distortions in the current and voltage waveforms were seen in scenarios 1 and 2, respectively. Furthermore, the harmonic spectrums at PCC for scenarios 1-4 are shown in Figure 15a,b. The highest levels of total harmonic distortion in voltage and current waveform, $\mathrm{THD}_{\mathrm{v}}$ and $\mathrm{THD}_{\mathrm{i}}$, at PCC were observed as 14.5 and $4.3 \%$, respectively. This level of $\mathrm{THD}_{\mathrm{i}}$ is significantly greater than the IEEE limits, i.e., $8 \%$ at PCC; therefore, this case cannot be considered as an optimum choice in terms of grid-connected rooftop solar $\mathrm{PV}$ installations.

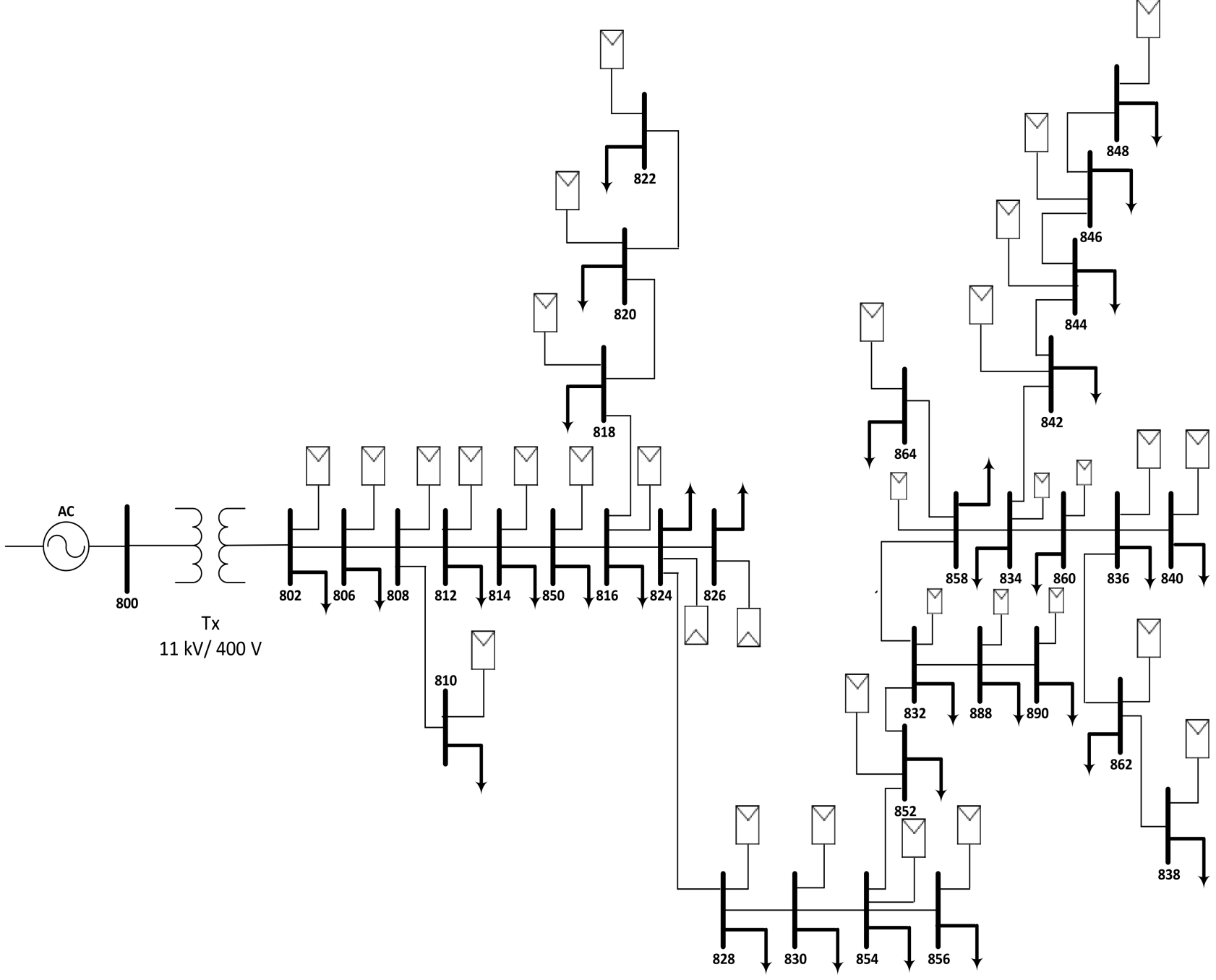

Figure 13. SLD of modified IEEE-34 bus distribution network with $100 \%$ PV penetration. 


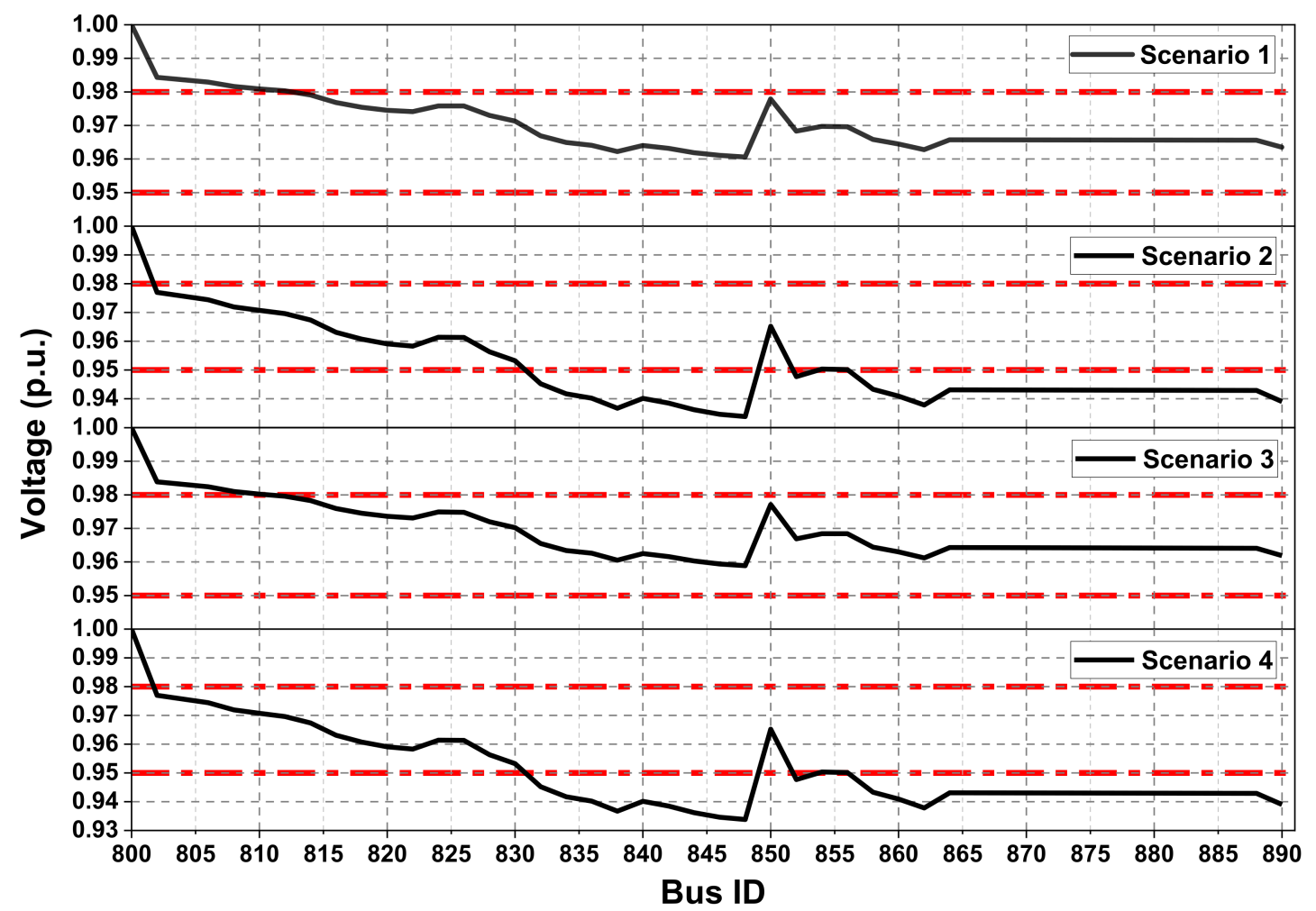

(a)
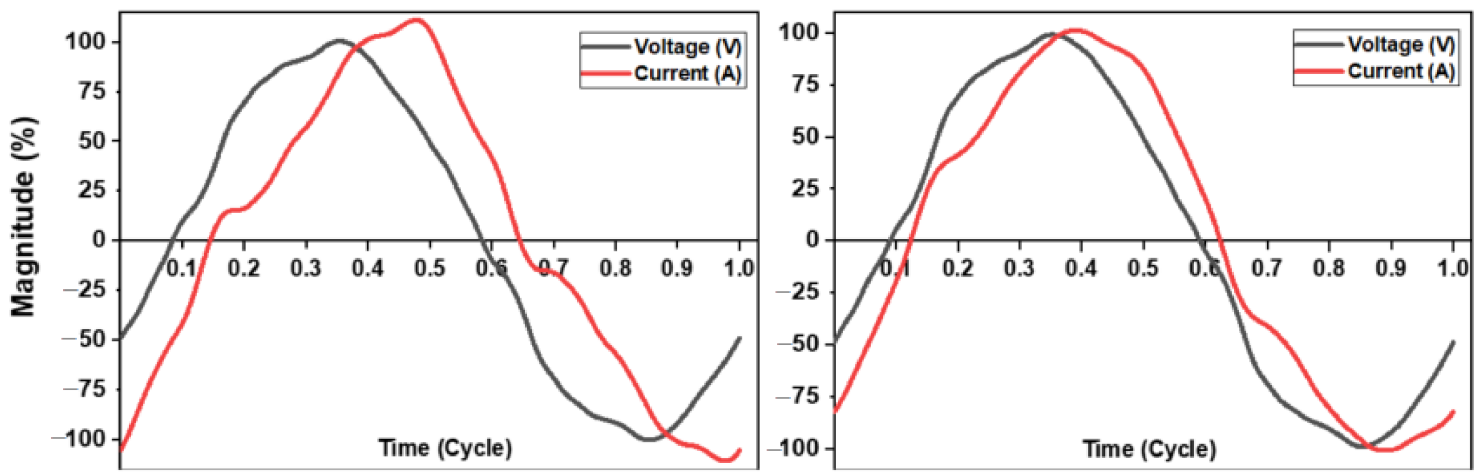

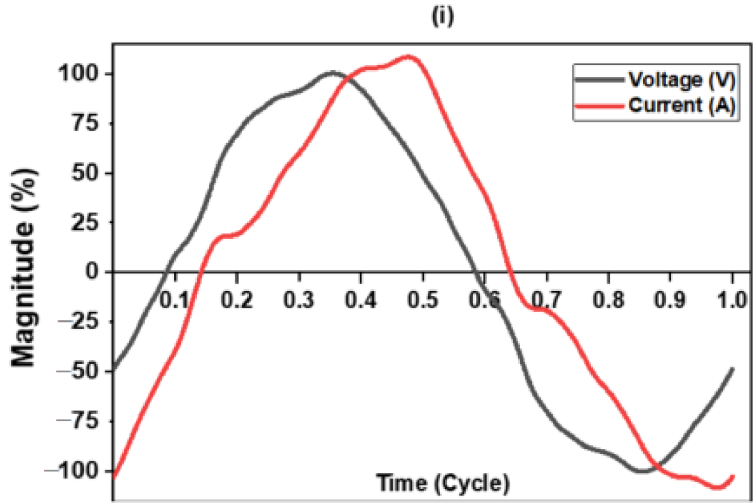

(iii)

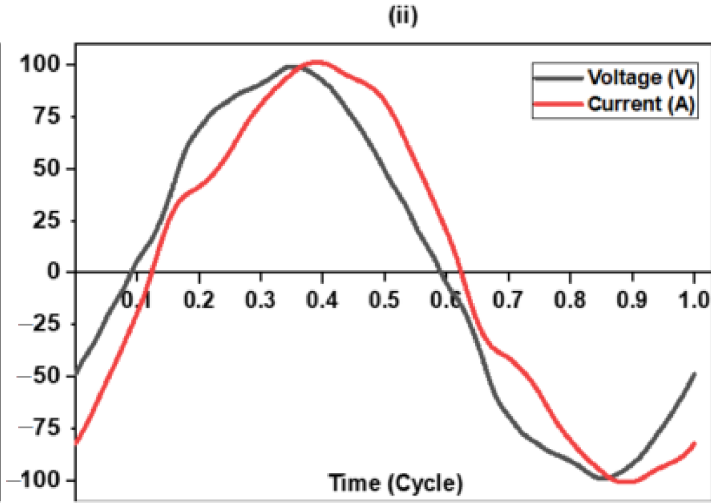

(iv)

(b)

Figure 14. (a) Per unit voltage profile of the distribution network for scenarios $1-4$ of case 3 (100\% PV penetration). (b) Voltage and current waveforms at PCC for a complete cycle for scenarios $1-4$ of case 3 (100\% PV penetration). 


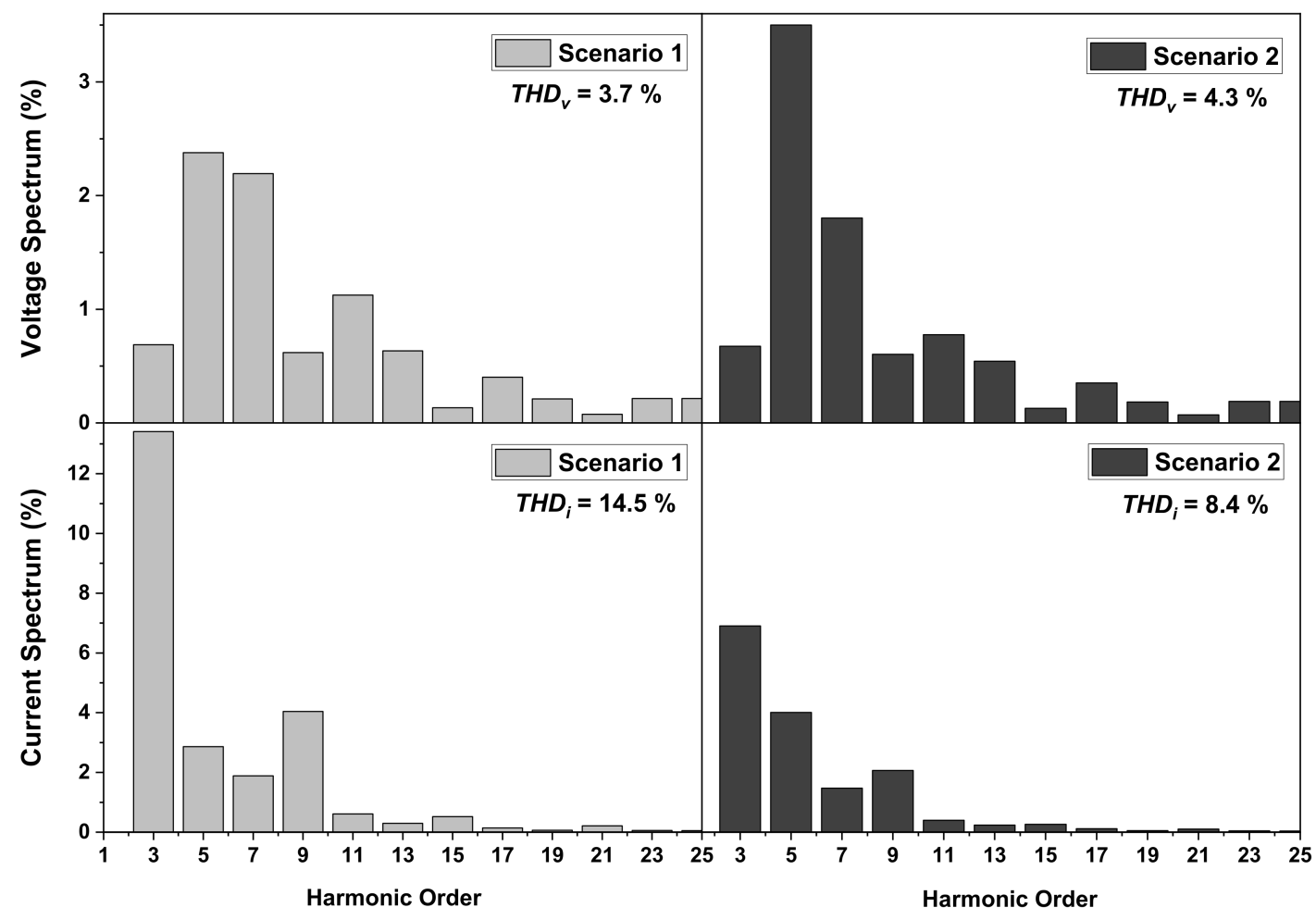

(a)

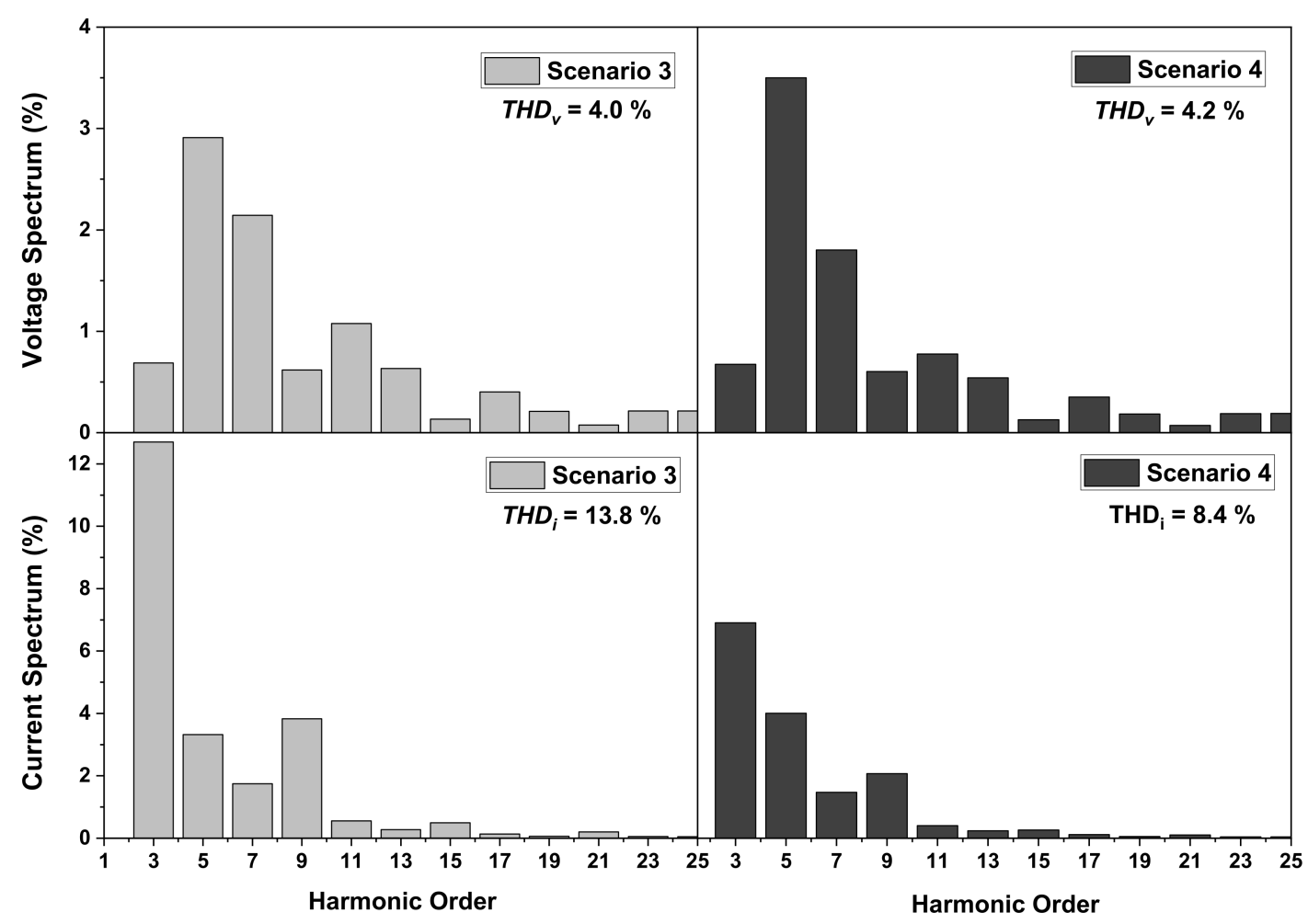

(b)

Figure 15. Voltage and current harmonic spectrum for case 3 along with $\mathrm{THD}_{\mathrm{v}}$ and $\mathrm{THD}_{\mathrm{i}}$ at $\mathrm{PCC}$ in (a) scenarios 1 and 2 and (b) scenarios 3 and 4 . 
The summary of active, reactive, and complex power losses for all cases and scenarios is given in Table 9. As can be seen, the maximum and minimum amount of percentage power losses with reference to total load at the LV network were obtained for cases 1 and 3 , respectively. Intermediate levels of power losses were observed for case 2 with 50\% PV penetration levels for all scenarios. Added to this, the highest amount of percentage power losses was noted for scenarios 2 and 4 when generation levels were low. Hence, it is suggested that the losses in the LV network can be minimized through high penetration levels of DG with high generation levels. However, the harmonic pollution levels at PCC also increases with the upcoming saturation of solar PV inverters.

Table 9. Total active $(\mathrm{kW})$, reactive (kVar), and apparent power loss (kVA) in percentage (\%) of total load of the network.

\begin{tabular}{|c|c|c|c|c|c|c|c|c|c|c|c|c|c|}
\hline \multirow{2}{*}{$\begin{array}{c}\text { Type of } \\
\text { Power Loss }\end{array}$} & \multirow{2}{*}{$\begin{array}{c}\text { Reference } \\
\text { Case(Case 0) }\end{array}$} & \multicolumn{4}{|c|}{ Case 1} & \multicolumn{4}{|c|}{ Case 2} & \multicolumn{4}{|c|}{ Case 3} \\
\hline & & S1 & $\mathrm{S} 2$ & S3 & S4 & S1 & S2 & S3 & S4 & S1 & $\mathrm{S} 2$ & S3 & S4 \\
\hline Active & 3.13 & 2.2 & 3.1 & 2.3 & 3.3 & 1.9 & 3.3 & 2.0 & 3.3 & 0.9 & 3.3 & 1.0 & 3.3 \\
\hline Reactive & 5.8 & 4.2 & 5.9 & 4.3 & 4.6 & 2.6 & 4.6 & 2.8 & 4.6 & 1.3 & 4.6 & 1.4 & 4.6 \\
\hline Apparent & 6.6 & 4.8 & 6.7 & 4.9 & 5.7 & 3.3 & 5.7 & 3.4 & 5.7 & 1.6 & 5.7 & 1.7 & 5.7 \\
\hline
\end{tabular}

\section{Conclusions}

This paper characterizes the potential harmonic impacts of grid-connected rooftop solar PV in the presence of diverse nonlinear load profiles of residential devices for a weak grid. The performance of the LV network was benchmarked based on the penetration levels of solar PV, varying from low $(0 \%)$ to high $(100 \%)$ with different seasonal generations along with the real load data. The total harmonic distortion in current and voltage waveforms $\left(\mathrm{THD}_{\mathrm{v}}\right.$ and $\left.\mathrm{THD}_{\mathrm{i}}\right)$ at PCC was compared to IEEE-2014 standards and observed as overall harmonic index pollution.

Although modern inverters have the ability to mitigate THD issues, there are no regulations to enforce this. Therefore, in this study, we modeled an off-the-shelf inverter typically used in rooftop solar PV installations. Further, cumulative $\mathrm{THD}_{\mathrm{i}}$ of multiple inverters installed at adjacent buses pollute the LV network with a significant amount of harmonic distortion in the current and voltage waveforms. Hence, the harmonic levels at PCC increases due to the nonlinear nature of output waveforms of the solar PV inverters.

It was concluded that case 2, with the installation of solar PV panels at alternate buses (50\% PV penetration) of the distribution system, serves as the optimum case. The highest $\mathrm{THD}_{\mathrm{i}}$ and $\mathrm{THD}_{\mathrm{v}}$ values of 10.2 and $5.2 \%$, respectively, are reasonably comparable to the IEEE benchmarks ( $8 \%$ for both $\mathrm{THD}_{\mathrm{v}}$ and $\mathrm{THD}_{\mathrm{i}}$ ). Additionally, the system's voltage profile was improved with significantly reduced losses of $1.9,2.6$, and 3.3\% for active, reactive, and apparent power, respectively, compared to the base case. This study presents a comparative analysis for installing grid-connected solar PV panels in a weak grid environment with real nonlinear household loads. It is suggested that the integration of rooftop solar PV panels at alternated nodes of the modified IEEE-34 bus system improves the voltage profile and minimizes the power losses and is in compliance with THD limits as per IEEE standards. The results further suggest that a comparative analysis enables the potential harmonic impacts of grid-connected solar PV to be investigated in countries with vast solar resources and increasing net metering benefits.

Further, the presented framework can be applied to multiple feeders in the LV network in future investigations. The load dynamics depending on the nature of the feeder may affect the overall harmonic pollution inserted into the distribution network. In addition, the cumulative harmonic analysis of nonlinear loads and solar PV across multiple feeders in the LV network would be an interesting future research thread. 
Author Contributions: Conceptualization, S.M.A.; methodology, S.M.A.; software, S.M.A., H.A.K., N.A.Z. and S.T.; validation, H.A.K., N.A.Z. and A.H.; formal analysis, S.M.A. and H.A.K.; investigation, H.A.K. and N.A.Z.; resources, H.A.K. and N.A.Z.; data curation, S.M.A.; writing—original draft preparation, S.M.A.; writing-review and editing, H.A.K. and S.M.A.; visualization, H.A.K., S.M.A. and S.T.; supervision, H.A.K. and N.A.Z.; project administration, H.A.K.; funding acquisition, H.A.K. All authors have read and agreed to the published version of the manuscript.

Funding: This research received no external funding.

Institutional Review Board Statement: Not applicable.

Informed Consent Statement: Not applicable.

Data Availability Statement: Not applicable.

Conflicts of Interest: The authors declare no conflict of interest.

\section{References}

1. Ahsan, S.M.; Khan, H.A.; Hassan, N.-U.; Arif, S.M.; Lie, T.-T. Optimized power dispatch for solar photovoltaic-storage system with multiple buildings in bilateral contracts. Appl. Energy 2020, 273, 115253. [CrossRef]

2. Ahsan, S.M.; Khan, H.A. Performance comparison of CdTe thin film modules with c-Si modules under low irradiance. IET Renew. Power Gener. 2019, 13, 1920-1926. [CrossRef]

3. Baig, M.Q.; Khan, H.A.; Ahsan, S.M. Evaluation of solar module equivalent models under real operating conditions-A review. J. Renew. Sustain. Energy 2020, 12, 12701. [CrossRef]

4. Kim, S.-K.; Jeon, J.-H.; Cho, C.-H.; Kim, E.-S.; Ahn, J.-B. Modeling and simulation of a grid-connected PV generation system for electromagnetic transient analysis. Sol. Energy 2009, 83, 664-678. [CrossRef]

5. Camilo, F.M.; Pires, V.F.; Castro, R.; Almeida, M. The impact of harmonics compensation ancillary services of photovoltaic microgeneration in low voltage distribution networks. Sustain. Cities Soc. 2018, 39, 449-458. [CrossRef]

6. Chidurala, A.; Saha, T.K.; Mithulananthan, N.; Bansal, R.C. Harmonic emissions in grid connected PV systems: A case study on a large scale rooftop PV site. In Proceedings of the 2014 IEEE PES General Meeting I Conference \& Exposition, National Harbor, MD, USA, 27-31 July 2014; pp. 1-5.

7. Elkholy, A. Harmonics assessment and mathematical modeling of power quality parameters for low voltage grid connected photovoltaic systems. Sol. Energy 2019, 183, 315-326. [CrossRef]

8. Eltawil, M.A.; Zhao, Z. Grid-connected photovoltaic power systems: Technical and potential problems-A review. Renew. Sustain. Energy Rev. 2010, 14, 112-129. [CrossRef]

9. Gabr, W.I.; Salem, W.A. Impact of grid connected photovoltaic system on total harmonics distortion (THD) of low voltage distribution network: A case study. In Proceedings of the 2018 Twentieth International Middle East Power Systems Conference (MEPCON), Cairo, Egypt, 18-20 December 2018; pp. 608-614.

10. Nassif, A.B.; Yazdanpanahi, H.; Torquato, R. Harmonic characterization of modern residential distributed energy resources. In Proceedings of the 2018 IEEE Canadian Conference on Electrical \& Computer Engineering (CCECE), Quebec, QC, Canada, 13-16 May 2018; pp. 1-4.

11. Nduka, O.S.; Pal, B.C. Harmonic domain modeling of PV system for the assessment of grid integration impact. IEEE Trans. Sustain. Energy 2017, 8, 1154-1165. [CrossRef]

12. Patsalides, M.; Stavrou, A.; Efthymiou, V.; Georghiou, G.E. Towards the establishment of maximum PV generation limits due to power quality constraints. Int. J. Electr. Power Energy Syst. 2012, 42, 285-298. [CrossRef]

13. Pereira, H.A.; Freijedo, F.D.; Silva, M.; Mendes, V.; Teodorescu, R. Harmonic current prediction by impedance modeling of grid-tied inverters: A 1.4 MW PV plant case study. Int. J. Electr. Power Energy Syst. 2017, 93, 30-38. [CrossRef]

14. Pinto, R.; Mariano, S.; Calado, M.D.R.; De Souza, J.F. Impact of rural grid-connected photovoltaic generation systems on power quality. Energies 2016, 9, 739. [CrossRef]

15. Sakar, S.; Balci, M.E.; Aleem, S.H.A.; Zobaa, A.F. Integration of large-scale PV plants in non-sinusoidal environments: Considerations on hosting capacity and harmonic distortion limits. Renew. Sustain. Energy Rev. 2018, 82, 176-186. [CrossRef]

16. Torquato, R.; Trindade, F.C.; Freitas, W. Analysis of the harmonic distortion impact of photovoltaic generation in Brazilian residential networks. In Proceedings of the 2014 16th International Conference on Harmonics and Quality of Power (ICHQP), Bucharest, Romania, 25-28 May 2014; pp. 239-243.

17. Fekete, K.; Klaic, Z.; Majdandzic, L. Expansion of the residential photovoltaic systems and its harmonic impact on the distribution grid. Renew. Energy 2012, 43, 140-148. [CrossRef]

18. Dghim, H.; El-Naggar, A.; Erlich, I. Harmonic distortion in low voltage grid with grid-connected photovoltaic. In Proceedings of the 2018 18th International Conference on Harmonics and Quality of Power (ICHQP), Ljubljana, Slovenia, 13-16 May 2018; pp. 1-6.

19. Miller, W.; Liu, A.; Amin, Z.; Wagner, A. Power quality and rooftop-photovoltaic households: An examination of measured data at point of customer connection. Sustainability 2018, 10, 1224. [CrossRef] 
20. Bagheri, P.; Xu, W.; Ding, T. A distributed filtering scheme to mitigate harmonics in residential distribution systems. IEEE Trans. Power Deliv. 2015, 31, 648-656. [CrossRef]

21. Elphick, S.T. The Modern Domestic Load and Its Impact on the electricity Distribution Network. Master's Thesis, University of Wollongong, Wollongong, NSW, Australia, 2011.

22. McLorn, G.; Laverty, D.; Morrow, D.J.; McLoone, S. Load and harmonic distortion characterization of modern low-energy lighting under applied voltage variation. Electr. Power Syst. Res. 2019, 169, 124-138. [CrossRef]

23. Neha, C.; Hegde, M.; Aher, V.; Hegde, V. Effect of home appliances on power quality of conventional grid. In Proceedings of the 2016 International Conference on Circuits, Controls, Communications and Computing (I4C), Bangalore, India, 4-6 October 2016; pp. 1-6.

24. Niitsoo, J.; Kilter, J.; Palu, I.; Taklaja, P.; Kütt, L. Harmonic levels of domestic and electrical vehicle loads in residential distribution networks. In Proceedings of the 2013 Africon, Pointe aux Piments, Mauritius, 9-12 September 2013; pp. 1-5.

25. Salles, D.; Jiang, C.; Xu, W.; Freitas, W.; Mazin, H.E. Assessing the collective harmonic impact of modern residential loads-Part I: Methodology. IEEE Trans. Power Deliv. 2012, 27, 1937-1946. [CrossRef]

26. Santiago, I.; Palacios-García, E.; Moreno-García, I.; De Castro, A.G.; Moreno-Munoz, A. Appliances in the residential sector: Economic impact of harmonic losses. In Proceedings of the 2017 11th IEEE International Conference on Compatibility, Power Electronics and Power Engineering (CPE-POWERENG), Cadiz, Spain, 4-6 April 2017; pp. 620-625.

27. Sun, Y.; Xie, X.; Zhang, L.; Li, S. A voltage adaptive dynamic harmonic model of nonlinear home appliances. IEEE Trans. Ind. Electron. 2019, 67, 3607-3617. [CrossRef]

28. Ye, G.; Nijhuis, M.; Cuk, V.; Cobben, J.F. Appliance-based residential harmonic load modelling. In Proceedings of the 2017 IEEE Manchester PowerTech, Manchester, UK, 18-22 June 2017; pp. 1-6.

29. Bhattacharyya, S.; Cobben, S.; Ribeiro, P.; Kling, W. Harmonic emission limits and responsibilities at a point of connection. IET Gener. Transm. Distrib. 2012, 6, 256-264. [CrossRef]

30. Niitsoo, J.; Taklaja, P.; Palu, I.; Kiitam, I. Modelling EVs in residential distribution grid with other nonlinear loads. In Proceedings of the 2015 IEEE 15th International Conference on Environment and Electrical Engineering (EEEIC), Rome, Italy, 10-13 June 2015; pp. 1543-1548.

31. Piccirilli, M.; Reatti, A.; Corti, F.; Kazimierczuk, M.K.; Ayachit, A.; De La Pierre, P.; Nepote, A. Distortion analysis and equivalent impedance estimation of a class-D full-wave rectifier. In Proceedings of the 2017 IEEE International Conference on Environment and Electrical Engineering and 2017 IEEE Industrial and Commercial Power Systems Europe (EEEIC/I\&CPS Europe), Milan, Italy, 6-9 June 2017; pp. 1-7.

32. Corti, F.; Laudani, A.; Lozito, G.M.; Reatti, A. Computationally efficient modeling of DC-DC converters for PV applications. Energies 2020, 13, 5100. [CrossRef]

33. Lupangu, C.; Bansal, R. A review of technical issues on the development of solar photovoltaic systems. Renew. Sustain. Energy Rev. 2017, 73, 950-965. [CrossRef]

34. Chidurala, A.; Saha, T.K.; Mithulananthan, N. Harmonic impact of high penetration photovoltaic system on unbalanced distribution networks-learning from an urban photovoltaic network. IET Renew. Power Gener. 2016, 10, 485-494. [CrossRef]

35. Kharrazi, A.; Sreeram, V.; Mishra, Y. Assessment techniques of the impact of grid-tied rooftop photovoltaic generation on the power quality of low voltage distribution network-A review. Renew. Sustain. Energy Rev. 2020, 120, 109643. [CrossRef]

36. IEEE. IEEE recommended practice and requirements for harmonic control in electric power systems. In IEEE Standards Association; IEEE Power and Energy Society: Piscataway, MJ, USA, 2014; p. 29.

37. Ahmad, A.; Kashif, S.A.R.; Saqib, M.A.; Ashraf, A.; Shami, U.T. Tariff for reactive energy consumption in household appliances. Energy 2019, 186, 115818. [CrossRef] 